\title{
An Experimental Study on the Placement of Reference Electrodes in Alkaline Polymer Electrolyte Membrane Fuel Cells
}

\author{
Rong Zeng,* Robert C. T. Slade, John R. Varcoe \\ Chemical Sciences, University of Surrey, Guildford GU2 7XH, UK
}

\begin{abstract}
The ability to accurately measure separate in situ anode and cathode overpotentials and impedance responses is still a source of debate when investigating fuel cells of planar configuration containing $<100 \mu \mathrm{m}$ thickness solid electrolytes and when using the common three electrode arrangement. The results obtained in this study indicate that the overpotentials and impedances of the anode and cathode can be successfully measured when using two spatially separated reference electrodes and when the cathode and anode of alkaline membrane electrode assemblies (for alkaline polymer electrolyte membrane fuel cells) are precisely and optimally misaligned. The frequency dependent response between the two reference electrodes is attributed to the membrane response and the "cross-talk" between anode and cathode.
\end{abstract}

Keywords: alkaline membrane fuel cells; in situ reference electrode; misalignment of MEA electrodes; electrochemical impedance spectroscopy; electrode overpotentials

\section{Introduction}

Fuel cells represent a key technology in the delivery of clean energy for a future sustainable society. Alkaline polymer electrolyte membrane fuel cells (APEMFC) are a disruptive technology promising the ability to use cheaper, more abundant, non-platinum catalysts [1,2]; there is also growing evidence of their ability to operate in the presence of carbonate anions $[3,4]$.

It is vitally important to understand the in situ single electrode performances during fuel cell testing of new materials and components. A reference electrode (RE) is required to measure the individual anode and cathode potentials in fuel cells but the applicability of the commonly used three electrode configuration 
alongside thin solid electrolytes is still being debated. The main concern is that the overpotentials and impedance responses (impedance spectra) of the anode or cathode are a function of RE position and the degree of misalignment of the active electrodes of the membrane electrode assembly (MEA); there have been extensive theoretical studies, involving simulation methods [5-13].

For the planar geometry commonly used in fuel cell research, the inactive portion of the electrolyte is approximately equipotential at a distance of more than three electrolyte thicknesses from the edge of the active region [7]. A slightly misaligned MEA strongly biases the potential of the inactive portion of the electrolyte [7] and, as a consequence, the potential of a reference electrode located in this inactive area is biased. This makes it impossible to measure the separate overpotential of an anode and a cathode accurately. The situation is worse when trying to separate the impedance responses (on introduction of a.c. signals) of an anode and a cathode from the whole cell response, as the potential distributions in thin electrolytes are frequency dependent [9,11-12].

The prior simulation studies [11] show that the impedance of a half-cell does not distort significantly when the active electrodes of a MEA are well aligned and the active electrodes of the MEAs have the same electronic properties i.e. with the same electronic resistance (R) and capacitance (C). However, when the active electrodes of the MEAs have different $\mathrm{R}$ and $\mathrm{C}$ characteristics, the impedance is distorted even when the electrodes are precisely aligned [9,12]; Cimenti et al. has discussed the simulation results on this topic in detail [11-12]. Five different cell geometries are commonly encountered in the literature [14], with pellet geometry and microfabricated microelectrode arrays being the two that are generally acknowledged to allow isolation of the impedance of working electrode; these geometries are, however, very different to the planar structure encountered in fuel cells.

The prior work of Piela et al. [15] found that the iR-free individual electrode overpotentials can be measured with planar structured MEAs when placing a RE in ionic contact with the active layer of the fuel cell electrode of interest; this cleverly avoids the interfering potential distributions within the electrolyte when the RE is in contact with the protruding part of the electrolyte. As the RE was placed in the electrode area, the sensed overpotential was characteristic of a local overpotential rather than an average electrode overpotential. These local overpotentials were related to the fuel cell operating conditions. However, the meaning of this local overpotential is ambiguous as it cannot be precisely defined due to the structure of the 
MEA that was used. This limits the application of REs when detecting the local overpotential of an electrode. On the other hand, the average overpotential of the electrode could only be measured under certain conditions: This limits the application of the RE when detecting the average overpotential of the electrode. Furthermore, it was also difficult to mould the RE into the system used.

The premise of this study is that the RE can be located in the inactive electrolyte area outside the MEA so that accurate average overpotential of the electrode can be measured. In this case, it is crucial to understand the role of the RE in a 3-electrode configuration with the application-relevant planar structure. In this study, the effect of the placement of the RE and the misalignment of the active electrodes of an alkaline MEA in an APEMFC were studied using multiple REs. The strategy employed to measure the genuine impedance of a working electrode using the 3-electrode method was to locate the RE as close as possible to working electrode. It is shown that the RE can be located at an equipotential surface close to the electrode under study simply by careful control and optimisation of the MEA electrode misalignment. The use of this method significantly alleviates electrolyte-derived distortions in the measured impedance spectra. Although the experiments were conducted using alkaline MEAs in APEMFCs, the proposed method, in principle, should be applicable to any type of fuel cell or other electrochemical energy conversion device with thin planar geometry.

\section{Experimental}

A Pd coated Pt wire containing absorbed H (denoted (Pt)PdH) was used as the RE. The preparation and stability of this novel reference electrode were as previously reported [16]. In brief, Pd was electrodeposited on the surface of Pt wire in aqueous $\left(\mathrm{NH}_{4}\right)_{2} \mathrm{PdCl}_{4}\left(0.04 \mathrm{~mol} \mathrm{dm}^{-3}\right)$ containing $\mathrm{HCl}$ (aq, 1.0 mol $\mathrm{dm}^{-3}$ ), using a current density of $30 \mathrm{~mA} \mathrm{~cm}{ }^{-2}$ (geometric). After deposition, the Pt/Pd electrode was initially charged at $30 \mathrm{~mA} \mathrm{~cm}{ }^{-2}$ for 15 min (electrode cleaning procedure) and then at $-30 \mathrm{~mA} \mathrm{~cm}{ }^{-2}$ for 15 min (H adsorption procedure) in either aqueous $\mathrm{KOH}\left(1 \mathrm{~mol} \mathrm{dm}^{-3}\right)$ or $\mathrm{H}_{2} \mathrm{SO}_{4}\left(\mathrm{aq}, 1 \mathrm{~mol} \mathrm{dm}^{-3}\right)$. The MEAs, radiation-grafted alkaline anion-exchange membranes (AAEM), alkaline ionomer, and fuel cell test procedures $\left(\right.$ at $50^{\circ} \mathrm{C}$ ) were as previously reported [17-18]. The AAEMs used in the experiment were 
designated S20 (20 $\mu \mathrm{m}$ thick when fully hydrated) and S80 (80 $\mu \mathrm{m}$ hydrated). To obtain a thicker AAEM (approximately $160 \mu \mathrm{m}$ thick when hydrated), $2 \times$ S80 were used and assembled in situ.

A Fuel Cell Test Station (Arbin instrument, USA) was used to keep the fuel cell running under controlled conditions, i.e. $T_{\text {cell }}=50^{\circ} \mathrm{C}$, flow rates $\left(\mathrm{H}_{2}\right.$ and $\left.\mathrm{O}_{2}\right)=400 \mathrm{~cm}^{3} \mathrm{~min}^{-1}$, relative humidity $\mathrm{RH}=$ $100 \%$, and no back pressurization. The potentials and impedances between the active electrodes of the MEAs and the RE, between different REs, and the cell potential and impedance spectra using the 2electrode (anode-cathode) method were simultaneously recorded on a 1470E/1455A CellTest system (Solartron Analytical, UK) with the simultaneous use of multiple channels. The impedance spectra were obtained over the frequency range $50 \mathrm{kHz}-100 \mathrm{mHz}$, recorded at 10 steps decade $^{-1}$, for each applied constant d.c. current. The potentials corresponding to a particular applied d.c. current were recorded before and after the impedance measurement to confirm that the cell and the reference electrode (RE) were stable; results were discarded if the cell potential varied by more than $20 \mathrm{mV}$. The open circuit voltages (OCV) of the cell and potentials vs. RE were also recorded before and after all impedance measurements to check if the RE potentials were still stable; results were discarded if the potential drift vs. RE was over $40 \mathrm{mV}$. The mean of cell voltage and the potential vs. RE were the average data when the cell was stable at each applied d.c. current step.

The different positions of the various REs and misplacement of the active electrodes of MEA used in this study are defined in Scheme 1. The size of the MEA electrodes are $25 \mathrm{~mm} \times 25 \mathrm{~mm}$ when fully aligned (symmetrical). When misaligned, the anode and cathode (of the same composition) had a geometric area $(25 \mathrm{~mm} \times \mathrm{D}$ ) with $\mathrm{D}$ was reduced from $25 \mathrm{~mm}$ to $20 \mathrm{~mm}$. When the electrodes of the MEA were misaligned, the electrolyte area in close proximity to the cathode is designated the cathode area, and the area in close proximity to the anode is designated the anode area. The different REs are denoted as $\mathrm{RE}_{\mathrm{i}}$ or $\mathrm{RE}_{\mathrm{j}}$; more specifically, the RE in the cathode area is denoted $\mathrm{RE}_{\mathrm{c}}$ and the RE in the anode area is denoted $\mathrm{RE}_{\mathrm{a}}$.

\section{Results and discussion}

3.1 Comparison of the novel (Pt)PdH RE to an established Ag/AgCl RE 
After the (Pt)PdH RE was charged with adsorbed $\mathrm{H}_{2}$, the stability of the novel (Pt)PdH RE was compared to an $\mathrm{Ag} / \mathrm{AgCl} \mathrm{RE}$ is shown in Figure 1. The potential of (Pt)PdH RE vs. $\mathrm{Ag} / \mathrm{AgCl} \mathrm{RE}$ was recorded in aqueous $\mathrm{H}_{2} \mathrm{SO}_{4}\left(1 \mathrm{~mol} \mathrm{dm}{ }^{-3}\right)$ and $\mathrm{KOH}\left(1 \mathrm{~mol} \mathrm{dm}^{-3}\right)$ without $\mathrm{H}_{2}$ purge. It was clear that there were two stable potentials when using the (Pt)PdH RE; this was caused by the $\mathrm{H}_{2}$ absorption property of the Pd as discussed in detail in our previous work [16], which also highlighted the stability of the (Pt)PdH RE in APEMFCs. This is confirmed again with the data presented in Figure 7: The potential of the (Pt)PdH $\mathrm{RE}$ did not change before and after the test. It is important that the high potential state of the (Pt)PdH RE is stable without the need to supply $\mathrm{H}_{2}$ as this allows for the RE to be easy moulded into the fuel cell system.

3.2 The overpotential of anode and cathode vs. different reference electrodes

Typical anode and cathode potentials vs. different REs, when the active electrodes of MEA were misaligned by $\mathrm{d}=2.5 \mathrm{~mm}$, are presented in Figure 2. The "kink" in the middle of the cell polarization curve was not caused by the use of the REs: No kinks are observed when other MEAs are tested using the same RE. This MEA was deliberately chosen because such unusual behaviour would allow clear indications of anode and cathode performances when the cell performance of the cell changed so dramatically. The directly measured cell voltage (2-electrode method) is equal to potential of cathode vs. $\mathrm{RE}_{\mathrm{c}}$ (or $\mathrm{RE}_{\mathrm{a}}$ ) minus potential of anode $v s . \mathrm{RE}_{\mathrm{c}}$ (or $\mathrm{RE}_{\mathrm{a}}$ ). The potential of anode $v s . \mathrm{RE}_{\mathrm{a}}$ (and $\mathrm{RE}_{\mathrm{c}}$ ) changed in a similar manner to the deterioration of the whole cell response at higher current densities. Although the overpotential of the cathode $v s . \mathrm{RE}_{\mathrm{a}}$ was much bigger than overpotential of cathode $v s . \mathrm{RE}_{\mathrm{c}}$, the overpotential of cathode $v s$. $\mathrm{RE}_{\mathrm{a}}$ or $\mathrm{RE}_{\mathrm{c}}$ changed less significantly when the performance of cell deteriorated. In all the tests conducted, the potential of the anode $v s . \mathrm{RE}_{\mathrm{i}}$ increased noticeably unlike the potential of cathode $v s . \mathrm{RE}_{\mathrm{i}}$, when the performance of cell deteriorated. This implies that the deterioration in cell performance was ascribed to the increasing overpotential of anode (i.e. the cell performance is primarily controlled by the overpotential of anode). However, there is a significant discrepancy between the potential of the anode (or the cathode) vs. $\mathrm{RE}_{\mathrm{a}}$ and $v s . \mathrm{RE}_{\mathrm{c}}$. The physical meaning of the difference in potential of the active electrode $v s . \mathrm{RE}_{\mathrm{a}}$ and $\mathrm{RE}_{\mathrm{c}}$ is unclear. To investigate, the cell configurations detailed in Scheme 1 were utilised. 


\subsection{Direct current (d.c.) experiments}

Figure 3 presents the idealized equivalent circuit descriptions of the fuel cells under test when the RE is located at different positions in the solid electrolyte. Points $\mathrm{i}$ and $\mathrm{j}$ represent the equipotential surfaces where the REs are located. Under d.c. conditions, pure resistances (R) are considered. In the discussions below, $\mathrm{V}$ represents the experimentally determined voltages and $\varphi$ represents the real potential. Hence, $\varphi_{\mathrm{a}}$ is the real potential of the anode, $\varphi_{\mathrm{c}}$ is the potential of cathode, $\varphi_{\mathrm{REi}}$ is the intrinsic potential of the RE at point i, $V_{A / B}$ is the experimental potential of "generic electrode $A$ " vs. "generic electrode B" (i.e. $V_{A / B}=V_{A}-V_{B}$ $\left.=-\left(V_{\mathrm{B}}-\mathrm{V}_{\mathrm{A}}\right)=-\mathrm{V}_{\mathrm{B} / \mathrm{A}}\right), \mathrm{V}_{\text {anode/REi }}$ is the experimental potential between anode and $\mathrm{RE}_{\mathrm{i}}, \mathrm{V}_{\text {cathode/REi }}$ is the experimental potential between cathode and $\mathrm{RE}_{\mathrm{i}}$, and $\mathrm{R}_{\text {cell }}$ is the resistance of the cell, which is assumed equal to the resistance of the membrane plus the contact resistance between the active electrodes and membrane (R). $\varphi_{\mathrm{REi}}=\varphi_{\mathrm{REj}}$ because the intrinsic potential of the reference electrodes are the same.

The intrinsic potential of the RE is set as the baseline reference in the below equations. Under d.c. conditions,

$$
\begin{array}{ll}
\mathrm{V}_{\text {anode/REi }}=\varphi_{\mathrm{a}}-\left(\varphi_{\mathrm{REi}}-\mathrm{IR}_{\mathrm{i} 1}\right) & 1.1 \\
\mathrm{~V}_{\text {cathode/REi }}=\varphi_{\mathrm{c}}-\left(\varphi_{\mathrm{REi}}+\mathrm{IR}_{\mathrm{i} 2}\right) & 1.2 \\
\mathrm{R}_{\text {cell }}=\mathrm{R}=\mathrm{R}_{\mathrm{i} 1}+\mathrm{R}_{\mathrm{i} 2}=\mathrm{R}_{\mathrm{j} 1}+\mathrm{R}_{\mathrm{j} 2} & 1.3 \\
\varphi_{\mathrm{REi}}=\varphi_{\mathrm{REj}} & 1.4 \\
\mathrm{~V}_{\text {cathode }}-\mathrm{V}_{\text {anode }} & =\mathrm{V}_{\text {cathode/REi }}-\mathrm{V}_{\text {anode/REi }} \\
& =\varphi_{\mathrm{c}}-\varphi_{\mathrm{a}}-\mathrm{IR}_{\mathrm{i} 2}-\mathrm{IR}_{\mathrm{i} 1}=\varphi_{\mathrm{c}}-\varphi_{\mathrm{a}}-\mathrm{I}\left(\mathrm{R}_{\mathrm{i} 1}+\mathrm{R}_{\mathrm{i} 2}\right) \\
& =\varphi_{\mathrm{c}}-\varphi_{\mathrm{a}}-\mathrm{IR}=\mathrm{V}_{\text {cell }}
\end{array}
$$

For REs at different position, the potential between the reference electrodes in the electric field is

$$
\begin{aligned}
\mathrm{V}_{\mathrm{REj} / \mathrm{REj}} & =\mathrm{V}_{\mathrm{REi}}-\mathrm{V}_{\mathrm{REj}}=\mathrm{V}_{\text {anode/REj }}-\mathrm{V}_{\text {anode/REi }} \\
& =\left(\varphi_{\mathrm{REi}}-\mathrm{IR}_{\mathrm{i} 1}\right)-\left(\varphi_{\mathrm{REj}}-\mathrm{IR}_{\mathrm{j} 1}\right)=\mathrm{I}\left(\mathrm{R}_{\mathrm{j} 1}-\mathrm{R}_{\mathrm{i} 1}\right)
\end{aligned}
$$

As $\mathrm{R}_{\mathrm{j} 1}-\mathrm{R}_{\mathrm{i} 1} \neq 0$, the potential between different reference electrodes changes linearly in terms of current. If $V_{R E i}-V_{R E j}>0$, then $R_{j 1}-R_{i 1}>0$ and the potential of $R E_{i}$ is therefore closer to anode potential. If $V_{R E i}-$ 
$V_{\mathrm{REj}}=0$ (the potential between the REs does not change in terms of current), then $R_{j 1}=R_{i 1}$ and this indicates that the reference electrodes are located at the equipotential surface of the electric field.

According to equation 1.5, the potential between the anode and cathode tested by the same RE is equal to the directly measured $V_{\text {cell, }}$, which is verified by the experimental results presented in Figure 2 (and consistent with a previous study [19]). As shown in equation 1.1 and 1.2, the tested potential between the active electrodes and the RE includes the partial potential loss of the electrolyte. This suggests that when $\mathrm{V}_{\text {cathode }}-\mathrm{V}_{\text {anode }}=\mathrm{V}_{\text {cell }}$, the measured potentials between the active electrodes and the RE fail to represent the true potential of the individual cell electrodes.

As the potential differences defined above involve partial potential losses due to the solid electrolyte, it is necessary to study the potential distribution within the electrolyte, more specifically the potential distribution in the inactive area of the membrane (outside the MEA active area). The different RE positions and misplacement of the active electrodes of MEA are defined in Scheme 1, with a typical result (for scenario (d) in Scheme 1) shown in Figure 4. The potential between the two REs increased or decreased approximately linearly as a function of current, which is consistent with equation 1.6. The results showed that the potential difference between two REs located in the same inactive area of the membrane (with misaligned MEA electrodes) were $<50 \mathrm{mV}$ when the REs were located $<9 \mathrm{~mm}$ apart and in the middle of the membrane (between 2 AAEMs pressed together). Similar results were achieved for the other experimental scenarios presented in Scheme 1. In brief, the potential distribution around a single inactive area of the membrane is pseudo-uniform (within the tolerances discussed above). The potential of a RE is not sensitive to the position within an inactive area, which is consistent with the previous studies [7] i.e. the potential outside the MEA, > $3 \times l$ (membrane thickness) away from the edge of the MEA, is uniform no matter whether the MEA electrodes were misaligned or not. As can be seen in Figure 4 with a misaligned MEA, $V_{\text {RE1/RE3 }}$ and $V_{\text {RE2/RE3 }}$ were positive and $V_{\text {RE5/RE4 }}$ was negative in terms of current. So the potential at the cathode area decreased slightly away from MEA edge, whilst the potential at the anode area increased slightly away from MEA edge (a phenomenon that may be caused by stray currents within the same inactive area).

Conversely, the potential difference between two REs located at different inactive areas (cathode area or anode area) changed significantly as a function of current ( $>200 \mathrm{mV}$ for $\mathrm{V}_{\mathrm{RE5} / \mathrm{RE3}}$ in Figure 4). The 
potential differences between REs in different inactive areas were typically in the range $60-200 \mathrm{mV}$. Figure 5 shows the potential difference between two REs located in different inactive area when the MEA electrodes were aligned as precisely as possible $(\mathrm{d}= \pm 0.5 \mathrm{~mm})$. For example $\mathrm{V}_{\mathrm{RE5} / \mathrm{RE2}}$ can be positive or negative (when the MEA electrodes were deliberately misaligned all such potentials were positive). The potential difference between RE5 and RE2 is therefore correlated to the misalignment of the MEA (due to its sensitivity to small degrees of misalignment). Based on our assumption, RE2 should be located in a higher potential area on MEA misalignment (i.e. the cathode area where RE2 is located has a higher potential and the anode area where RE5 is located has a lower potential). On the basis of the experimental observations, the potential distribution at the inactive areas of the membrane is suggested in Figure 6.

When the current is stepped from one current to another, there is always a delayed potential response as shown in Figure 7, with MEA misalignments of $1.5-2 \mathrm{~mm}$ (scheme $1 \mathrm{~d}$ ). $\mathrm{OCV}_{\mathrm{b}}$ represents the open circuit voltage (OCV) before the fuel cell had undergone current discharge, and $\mathrm{OCV}_{\mathrm{a}}$ represents the OCV after the cell testing was complete. Times of $100 \mathrm{~s}$ or more were often required to obtain stabilized potentials. Hence, using voltammetric sweep measurements will involve errors even with scan rates as slow as $5 \mathrm{mV}$ $\mathrm{s}^{-1}$. To alleviate errors originating from the voltage transients, the fuel cells were discharged under constant current mode with MEAs misaligned at $\mathrm{d} \leq \pm 0.5 \mathrm{~mm}$ (aligned), $\mathrm{d}=1.5-2.0 \mathrm{~mm}, 2.5-3.0 \mathrm{~mm}, 5.0-5.5$ mm (Figure 8). The solid electrolyte used was two $2 \times$ S80 AAEMs assembled together in situ with the REs located between the two membranes to lower the contact resistance between RE and the membrane. The error bars in Figure 8 indicate the maximum drift of the potentials during each test step with each constant current discharge when the cell is "stable" (typical shifts of $5-20 \mathrm{mV}$ ). The standard deviations of the recorded potentials were typically less than $\pm 8 \mathrm{mV}$. The potentials between the anode and the $\mathrm{RE}$ at anode area was denoted as $\mathrm{V}_{\mathrm{a}}$, between the cathode and the RE at cathode area was denoted as $\mathrm{V}_{\mathrm{c}}$, and between the RE at anode area and the RE at cathode area was denoted as $\mathrm{V}_{\mathrm{REa} / \mathrm{REc}}$. $\mathrm{V}_{\mathrm{REa} / \mathrm{REc}}$ increased linearly with current and the slope of the linear regression line was less than the cell resistance measured using the electrochemcial impedance spectroscopy (EIS) method [2] when $\mathrm{d} \leq \pm 0.5 \mathrm{~mm}$ (aligned MEA). However, the slopes matched the EIS cell resistances well (close to the IR line) when the MEA mismatch was increased to $\mathrm{d}=1.5-2.0 \mathrm{~mm}$. The $\mathrm{V}_{\mathrm{REa} / \mathrm{REC}}$ regression lines were $c a .50 \mathrm{mV}$ higher, but parallel to, the IR plots with increased misalignment (when $\mathrm{d}=2.5-3.0 \mathrm{~mm}$ and $5.0-5.5 \mathrm{~mm}$ ). As the slopes of $\mathrm{V}_{\mathrm{REa} / \mathrm{REc}}$ 
vs. current matched $\mathrm{R}_{\text {cell }}$ values with MEA misalignments of $\geq 1.5 \mathrm{~mm}$, it is hypothesised that the potential difference between $\mathrm{RE}_{\mathrm{a}}$ and $\mathrm{RE}_{\mathrm{c}}$ originated from $\mathrm{R}_{\text {cell }}$. Generally the $\mathrm{R}_{\text {cell }}$ includes electronic, ionic and contact resistances. Based on the results, it is reasonable to hypothesize that $\mathrm{R}_{\text {cell }}$ mainly consists of the membrane resistance and the contact resistances between the active electrodes and the membrane. The misalignment of the MEA locates $\mathrm{RE}_{\mathrm{c}}$ at an equipotential surface that is close to the potential of cathode (and vice versa for the $R E_{a}$ ). When the MEA is misaligned by $\geq 1.5 \mathrm{~mm}, \mathrm{RE}_{\mathrm{a}}$ and $\mathrm{RE}_{\mathrm{c}}$ are hypothesised to be at the equipotential surfaces shown in Figure 3(b).

When the MEA was deliberately misaligned from $\pm 0.5 \mathrm{~mm},\left(\mathrm{~V}_{\mathrm{c}}-\mathrm{V}_{\mathrm{a}}\right)$ went from being $<\left(\mathrm{V}_{\text {cell }}+\mathrm{IR}\right)$ in the aligned state to $\left(\mathrm{V}_{\mathrm{c}}-\mathrm{V}_{\mathrm{a}}\right)=\left(\mathrm{V}_{\text {cell }}+\mathrm{IR}\right)$ with $\mathrm{d}=1.5-2 \mathrm{~mm}$ (where the slope of $\mathrm{V}_{\mathrm{REa} / \mathrm{REc}}$ was also equal to $\left.\mathrm{R}_{\text {cell }}\right)$. The values of $\left(\mathrm{V}_{\mathrm{c}}-\mathrm{V}_{\mathrm{a}}\right)$ measured were about $50 \mathrm{mV}$ greater than $\left(\mathrm{V}_{\text {cell }}+\mathrm{IR}\right)$ when the MEA misalignment was increased to $2.5-3.0 \mathrm{~mm}$ and $5-5.5 \mathrm{~mm}$. The test was repeated several times with $\mathrm{d}=$ $2.5 \mathrm{~mm}$ and $\left(\mathrm{V}_{\mathrm{c}}-\mathrm{V}_{\mathrm{a}}\right)$ was always ca. $50 \mathrm{mV}$ greater than $\left(\mathrm{V}_{\text {cell }}+\mathrm{IR}\right)$; this cannot be written off as simply the indeterminate errors of the test.

The experimental results presented above suggest that there are two critical misalignment regimens: (1) $\mathrm{d} \approx 0 \mathrm{~mm}$ and (2) $\mathrm{d}=1.5-2 \mathrm{~mm}$. When $\mathrm{d}$ was within $\pm 0.5 \mathrm{~mm}$, the potential between REs in different active areas changed significantly in terms of current (positive or negative depending on if $\mathrm{d}>0 \mathrm{~mm}$ or $<0$ $\mathrm{mm})$. When $\mathrm{d}>1.5-2.0 \mathrm{~mm},\left(\mathrm{~V}_{\mathrm{c}}-\mathrm{V}_{\mathrm{a}}\right)$ increased to $50 \mathrm{mV}$ higher than $\left(\mathrm{V}_{\text {cell }}+\mathrm{IR}\right)$ where it remained unchanged even when $d$ was increased to $5-5.5 \mathrm{~mm}$. When misalignment was $1.5-2 \mathrm{~mm},\left(\mathrm{~V}_{\mathrm{c}}-\mathrm{V}_{\mathrm{a}}\right)$ was very close to $\left(\mathrm{V}_{\text {cell }}+\mathrm{IR}\right)$. If we measure the potential of anode $v s$. $R E_{\mathrm{a}}$ and the potential of cathode $v s$. $R E_{c}$ with $+1.5 \mathrm{~mm}$ misalignment of the MEA electrodes, reasonably accurate values of the anode and cathode overpotentials can be determined. The difference between $\left(V_{c}-V_{a}\right)$ and $\left(V_{\text {cell }}+I R\right)$ is a useful parameter to judge if the electrodes of MEA are optimally misaligned.

In summary, the potential between anode and cathode was separated into three components with the use of two REs located in the anode and cathode inactive areas respectively, and with misalignment of the MEA such that $\left(V_{c}-V_{a}\right)=\left(V_{\text {cell }}+I R\right)$, i.e. $V_{\text {tot }}=\left|V_{c}\right|+\left|V_{a}\right|+\left|V_{m}\right|=\varphi_{c}-\varphi_{a}-I R$. In this case, $R E_{a}$ and $R E_{c}$ were located at an equipotential surface depicted in Figure $3(\mathrm{~b}) . \mathrm{V}_{\mathrm{c}}$ and $\mathrm{V}_{\mathrm{a}}$ adequately represent the potentials of cathode and anode respectively. The difference between the electrode potentials vs. RE $E_{a}$ and $\mathrm{RE}_{\mathrm{c}}$ (shown in Figure 2) is caused by the IR drop of membrane and the contact resistance between the 
active electrodes and the membrane. The potential between cathode vs. $\mathrm{RE}_{\mathrm{c}}$ and the potential between anode $v s . \mathrm{RE}_{\mathrm{a}}$ will represent the real potential of the cathode and anode with optimal MEA misalignment.

Tsutsum et al. [20] also suggest the misalignment of the MEA to exclude the effect of the cell internal resistance so that the potential of a single electrode can be measured. This is highly consistent with our study. As shown in Fig. 8(a), a slightly misaligned MEA $(\leq 0.5 \mathrm{~mm})$ significantly reduces the effect of the cell resistance as there is only about $30 \mathrm{mV}$ difference between $\left(\mathrm{V}_{\mathrm{c}}-\mathrm{V}_{\mathrm{a}}\right)$ and $\left(\mathrm{V}_{\text {cell }}+\mathrm{IR}\right)$. This means it is possible to record the potentials of single electrodes with MEA misalignments of $0.5 \mathrm{~mm}$. However, such small misalignments are not enough to record the a.c. impedance spectrum of a single electrode (this will be discussed in detail in section 3.4). A non-systemic study (not shown in this paper) suggests that the best misalignment distance $\mathrm{d}$ is related to membrane thickness $\mathrm{L}$. It is important to find the relationship between the misalignment distance $\mathrm{d}$ and $\mathrm{L}$ so that a general criterion can be applied to different systems where the membrane thicknesses are different. This needs a more precise alignment technology current impossible for our state-of-the-art MEA preparing process, this will be discussed in a later study.

\subsection{Alternating current (a.c.) experiments (electrochemical impedance spectroscopy, EIS)}

For the a.c. experiments with constant d.c. current discharges, small a.c. current perturbations were applied to the system under load. The impedance of the reference electrode was very small and is assumed to not change in terms of frequency. As described in equation $1.1, \mathrm{~V}_{\text {anode/REi }}=\varphi_{a}-\left(\varphi_{\mathrm{REi}}-\mathrm{IR}_{\mathrm{i} 1}\right)$. When an a.c. current signals were introduced, only a.c. potential (and current) responses were recorded. The a.c. potential signal recorded was $\tilde{U}$ anode/REi $=\psi_{\mathrm{a}}+\tilde{\mathrm{IZ}} \mathrm{Z}_{\mathrm{i} 1}$ where $\tilde{\mathrm{U}}, \psi_{\mathrm{a}}$, Ĩ and $\mathrm{Z}$ represent, respectively, the a.c. response of the measured potential, the real a.c. potential response of the anode, the total a.c. cell current and the impedance of membrane and contact resistance between the active electrodes and membrane. Even if the electrolyte resistance does not change with frequency $(Z=R)$, IIR is still frequency dependent because of the term Ĩ. At a given frequency (f), electrodes with very different time constants will generate different potential distributions at the electrode/electrolyte interfaces, causing the potential distributions inside the electrolyte to change with frequency [11-12]. This leads to a complicated influence of the electrolyte on the EIS responses. As shown above in Figure 3(b), when the electrodes of MEA are controllably misaligned, 
$R_{i 1}=R_{j 2}=0, R_{j 1}=R_{i 2}=R$, and so as $Z_{i 1}=Z_{j 2}=0, Z_{j 1}=Z_{i 2}=Z$. So, $\tilde{U}_{\text {anode/REi }}=\psi_{a}$, which means that the impedance spectrum acquired $v s . \mathrm{RE}_{\mathrm{i}}$ at the equipotential surface in the anode active area in close proximity to the anode is the true impedance of anode (and vice versa for impedance of cathode).

Under the conditions defined in Figure 3(a),

$$
\begin{aligned}
& \tilde{\mathrm{U}}_{\text {anode/REi }}=\psi_{\mathrm{a}}+\tilde{\mathrm{IZ}}_{\mathrm{i} 1} \\
& \tilde{\mathrm{U}}_{\text {cathode/REj }}=\psi_{\mathrm{c}}-\tilde{\mathrm{I}} \mathrm{Z}_{\mathrm{j} 2} \\
& \tilde{\mathrm{U}}_{\mathrm{RE} / \mathrm{REj}}=\tilde{\mathrm{I}}_{\mathrm{j} 1}-\tilde{\mathrm{I}} \mathrm{Z}_{\mathrm{i} 1} \\
& \mathrm{Z}=\mathrm{Z}_{\mathrm{i} 1}+\mathrm{Z}_{\mathrm{i} 2}=\mathrm{Z}_{\mathrm{j} 1}+\mathrm{Z}_{\mathrm{j} 2}
\end{aligned}
$$

When using a single RE,

$$
\begin{gathered}
\tilde{\mathrm{U}}_{\text {cathode/REi }}-\tilde{\mathrm{U}}_{\text {anode/REi }}=\psi_{\mathrm{c}}-\psi_{\mathrm{a}}-\tilde{\mathrm{I}} \mathrm{Z}_{\mathrm{i} 2}-\tilde{\mathrm{I}} \mathrm{Z}_{\mathrm{i} 1}=\psi_{\mathrm{c}}-\psi_{\mathrm{a}}-\tilde{\mathrm{I}}\left(\mathrm{Z}_{\mathrm{i} 1}+\mathrm{Z}_{\mathrm{i} 2}\right) \\
=\psi_{\mathrm{c}}-\psi_{\mathrm{a}}-\tilde{\mathrm{I} Z}=\tilde{\mathrm{U}}_{\text {cell }}
\end{gathered}
$$

When using two REs, $\tilde{\mathrm{U}}_{\text {cathode/REi, }}, \tilde{\mathrm{U}}_{\text {anode/REi }}$ and $\tilde{\mathrm{U}}_{\mathrm{REi} / \mathrm{REj}}$ were measured,

$$
\begin{aligned}
& \tilde{\mathrm{U}}_{\text {cathode/REj }}-\tilde{\mathrm{U}}_{\text {anode/REi }}-\tilde{\mathrm{U}}_{\mathrm{RE} / R E j} \\
&=\psi_{\mathrm{c}}-\tilde{\mathrm{I}} \mathrm{Z}_{\mathrm{j} 2}-\psi_{\mathrm{a}}-\tilde{\mathrm{I}} \mathrm{Z}_{\mathrm{i} 1}-\tilde{\mathrm{I}} \mathrm{Z}_{\mathrm{j} 1}+\tilde{\mathrm{I}} \mathrm{Z}_{\mathrm{i} 1} \\
&=\psi_{\mathrm{c}}-\psi_{\mathrm{a}}-\tilde{\mathrm{I}}\left(\mathrm{Z}_{\mathrm{j} 1}+\mathrm{Z}_{\mathrm{j} 2}\right) \\
&=\psi_{\mathrm{c}}-\psi_{\mathrm{a}}-\tilde{\mathrm{I} Z}=\tilde{\mathrm{U}}_{\mathrm{cell}}
\end{aligned}
$$

When the two REs located at the equal potential positions in Figure 3(b),

$$
\begin{aligned}
& \mathrm{Z}_{\mathrm{i} 1}=\mathrm{Z}_{\mathrm{j} 2}=0, \mathrm{Z}_{\mathrm{j} 1}=\mathrm{Z}_{\mathrm{i} 2}=\mathrm{Z} \\
& \tilde{\mathrm{U}}_{\text {cathode/REc }}-\tilde{\mathrm{U}}_{\text {anode/REa }}-\tilde{\mathrm{U}}_{\mathrm{REi} / \mathrm{REj}} \\
& \quad=\psi_{\mathrm{c}}-\psi_{\mathrm{a}}-\tilde{\mathrm{I}} \mathrm{Z}=\tilde{\mathrm{U}}_{\text {cell }}
\end{aligned}
$$

The equations above suggest that

$$
\begin{aligned}
& \mathrm{Z}_{\text {tot }}=\tilde{\mathrm{U}}_{\text {cell }} / \tilde{\mathrm{I}}=\mathrm{Z}_{\text {cathode/REi }}+\mathrm{Z}_{\text {REj/anode }} \\
& \mathrm{Z}_{\text {tot }}=\tilde{\mathrm{U}}_{\text {cell }} / \tilde{\mathrm{I}}=\mathrm{Z}_{\text {cathode/REj }}+\mathrm{Z}_{\mathrm{REi} / \text { anode }}+\mathrm{Z}_{\mathrm{REj} / \mathrm{REi}}
\end{aligned}
$$

Equations 1.15 and 1.16 are consistent with the experimental results obtained where the calculated total cell impedance spectra (sum of the impedance spectra listed above) were equal to the measured whole cell impedance spectra (simultaneously recorded between the anode and cathode using the 2-electrode method), apart from small discrepancies at high frequencies (Figure 9 - 10 relates to equation 1.15, Figure 11 relates 
to equation 1.16). Equation 1.15 is also consistent with previous studies $[20,21]$ that showed that the sum of the anode and cathode impedance spectra vs. the same RE was equal to the impedance spectrum of the cell.

The a.c. impedance spectra vs. different REs would only be the same if the REs are located at the same equipotential surface under a.c. conditions. Figure 9 shows the results when REs located in the same inactive area (Figure 9 should be consulted alongside Scheme 1) with aligned anode and cathode. The potentials between REs at opposite points of the same inactive area changed less than $5 \mathrm{mV}$ as a function of current, which was smaller than the potential drifts of the REs (not shown in Figure 4 for clarity). Figure 9(a) clearly shows that the impedance spectra vs. different REs were the same, with aligned anode and cathode (Scheme 1a); this was also true with misaligned anode and cathode (Scheme 1c). However in Figure 9(b) with misalignment of $d=2.5 \mathrm{~mm}$, the EIS spectra parallel shifted but with retention of the spectral form (shape). These observations occurred with all the scenarios depicted in Scheme 1 when different REs were located in the same inactive area. The sum of the anode and cathode impedances vs. the same RE (denoted as Calcul Cell in Figure 9) matched the measured whole cell impedance (2-electrode measurement). The impedance spectral features vs. different REs located in the same inactive area remained effectively the same in shape and magnitude, which means they are insensitive to the position of REs in the same inactive area. This also suggests that the REs are located on comparatively equipotential surfaces in these a.c. experiments. As long as there is only a small potential difference between the two reference electrodes as a function of current, there were only small differences in the form of the resulting impedance spectra; the resistances measured from the high-f $x$-axis intercepts were, however, sensitive to the small potential differences between the two reference electrodes.

This situation was very different when the REs were located in different inactive areas. Despite the potential difference of such REs being $<50 \mathrm{mV}$ at $360 \mathrm{~mA} \mathrm{~cm}$ (Figure 5(b)) with well aligned MEAs, the impedance spectra obtained vs. the different REs were markedly different (Figure 10). As discussed in section 3.3 (and defined in Scheme 1), RE5 is located at the cathode inactive area while RE2 is located at the anode inactive area. It was clear that, even at a low current density of $40 \mathrm{~mA} \mathrm{~cm}{ }^{-2}$, there was a clear difference between the cathode impedance spectra vs. RE5 and vs. RE2 (Figure 10(a)). The impedance of the anode did not conspicuously change (as it was larger in magnitude), whilst the impedance of the cathode vs. the different REs was radically different at $240 \mathrm{~mA} \mathrm{~cm}{ }^{-2}$ (Figure 10(b)). The cathode 
impedance spectrum vs. RE2 contained a substantial inductive loop at lower frequencies. These results suggest that the potential distributions within inactive areas are uniform under both a.c. and d.c. test conditions, but are substantially different between different inactive areas under a.c. test conditions (even if the potential differences between different inactive area was small under d.c. test conditions). This suggests that the potential distribution within the cathode inactive area is dominated by the cathode and is uniform with both d.c. and a.c. test conditions (vice versa with regards to the anode inactive area). This also suggests that the potential distributions under d.c. conditions correspond to the potential distributions under a.c. conditions as the potential difference between REs located at different inactive areas is different from the potential differences between REs within the same inactive area (one represents the IR drop or partial IR drop of the membrane, one represents the potential difference caused by stray currents).

The impedance spectrum of the cathode vs. RE2 (Figure 10(b) inset) was equal to the sum of the cathode vs. RE5 and RE5 vs. RE2 impedance spectra (also true for anode spectra), and hence the differences between the impedance spectra of the cathode (anode) vs. different REs derive from the different responses of the two REs. For more clarity, Figure 11 shows two typical measurements of the effect of the RE response between $\mathrm{RE}_{\mathrm{i}}$ and $\mathrm{RE}_{\mathrm{j}}$ when located within the cathode inactive area (Figure 11(a)) and at different inactive areas(Figure 11(b)); the small and big differences between the electrode impedance spectra vs. different REs, when the REs were co-located within the same inactive area (Figure 9(b)) and when located at different inactive areas respectively (Figure 10), can be accounted for by the differences in response between the two REs. The impedance spectra of the cathode vs. $\mathrm{RE}_{c}$ and $\mathrm{RE}_{\mathrm{a}}$, and anode $v s . \mathrm{RE}_{c}$ and $\mathrm{RE}_{\mathrm{a}}$ with MEA misalignment of $d=1.5-2.0 \mathrm{~mm}$ are presented in Figure 12. Due to the MEA symmetry, the impedance of the electrode $v s . R E_{c}$ relates to $d=1.5-2.0 \mathrm{~mm}$, whilst the impedance of the electrode $v$. $R E_{a}$ relates to $d=-(1.5-2.0) \mathrm{mm}$. The impedance spectrum of the cathode vs. $R E_{a}$ is right-shifted compared to the cathode $v s . \mathrm{RE}_{\mathrm{c}}$ with an arc of increased magnitude and a manifest low-f inductive loop; the impedance spectrum of the anode $v s . \mathrm{RE}_{\mathrm{c}}$ is right-shifted compared to the spectrum of the anode vs. $\mathrm{RE}_{\mathrm{a}}$ (identical right-shift magnitude to that observed on switching to the cathode $v s$. $\mathrm{RE}_{\mathrm{a}}$ from the cathode vs. $\mathrm{RE}_{\mathrm{c}}$ responses). The high frequency resistances (high- $\mathrm{f} x$-axis intercept) of the anode (also cathode) vs. $\mathrm{RE}_{\mathrm{a}}$ and $\mathrm{RE}_{\mathrm{c}}$ were clearly different; the anode/RE $\mathrm{E}_{\mathrm{c}}$ response had a similar profile compared to the anode $v s$. $\mathrm{RE}_{\mathrm{a}}$ response and was only slightly bigger in magnitude. This behaviour compares well to the results 
reported from prior simulation studies [11-12]. The inset in Figure 12 gives the impedance response between $\mathrm{RE}_{c}$ and $\mathrm{RE}_{\mathrm{a}}$; this was comparable in magnitude to cathode $v s . \mathrm{RE}_{\mathrm{a}} / \mathrm{RE}_{\mathrm{c}}$ responses but was much smaller than anode vs. $\mathrm{RE}_{\mathrm{a}} / \mathrm{RE}_{\mathrm{c}}$ responses. There was a significant difference between the impedance spectra of cathode $v s . \mathrm{RE}_{\mathrm{a}}$ and $v s . \mathrm{RE}_{\mathrm{c}}$, but only a slight difference between the impedance spectrum of anode $v s . \mathrm{RE}_{\mathrm{a}}$ and $v s . \mathrm{RE}_{\mathrm{c}}$. This again confirms that the difference between the impedance spectra of each electrode vs. different REs was caused by the differing responses of the two REs.

The MEAs with different anode-cathode misalignments had different impedance responses (Figure 13(a); related d.c. performances are found in Figure 8), whilst the overpotential of the cathode $v$ s. $\mathrm{RE}_{\mathrm{c}}$ did not change significantly. As this implies that the cathode responses in all tests were similar, the cathode responses can be used to judge the effect of MEA misalignment. The impedance response of the cathode vs. $\mathrm{RE}_{\mathrm{c}}$ became smaller in magnitude from $0<\mathrm{d}<0.5 \mathrm{~mm}$ to $\mathrm{d}=2.5-3.0 \mathrm{~mm}$, but then stabilised in magnitude (with a similar profile) for $\mathrm{d}=2.5-5.5 \mathrm{~mm}$, as presented in Figure 13(b); this is consistent with the d.c. results (when $\mathrm{d}=2.5-5.5 \mathrm{~mm},\left(\mathrm{~V}_{\mathrm{c}}-\mathrm{V}_{\mathrm{a}}\right)-\left(\mathrm{V}_{\text {cell }}+\mathrm{IR}\right)=c a .50 \mathrm{mV}$ and did not increase further). The significant low frequency semicircles in the impedance spectra of the cathode with $\mathrm{d}=2.5-3.0 \mathrm{~mm}$ and $\mathrm{d}=5.0-5.5 \mathrm{~mm}$ in Figure 13(b) correlate with the mass transport phenomena that are typically observed in such cells. However, the medium frequency semicircle at $d=1.5-2.0 \mathrm{~mm}$ was larger than that at $\mathrm{d}=2.5-$ 3.0mm and $5.0-5.5 \mathrm{~mm}$; this is further confirmation of the earlier assertion that the observation that $\left(\mathrm{V}_{\mathrm{c}}-\right.$ $\mathrm{V}_{\mathrm{a}}$ ) was $50 \mathrm{mV}$ higher than $\left(\mathrm{V}_{\text {cell }}+\mathrm{IR}\right)$ was not due to indeterminate experiment-derived errors.

The results discussed above for the a.c. experiments correlate well to those obtained in the d.c. studies. The overpotential of each electrode under d.c. discharge determined the impedance spectrum of that electrode. Analysis of the d.c. responses suggest that the impedance spectra recorded for the cathode vs. $\mathrm{RE}_{\mathrm{c}}$ and anode vs. $\mathrm{RE}_{\mathrm{a}}$ do represent the true impedance responses of the cathode and anode with an optimally misaligned MEA ( $\mathrm{d}=1.5-2.0 \mathrm{~mm}$ with the cell configuration and the MEAs used in this study). Although the impedance spectrum of cathode was similar when $d=2.5-5.5 \mathrm{~mm}$, an underestimation of the impedance of the electrode is possible because $\left(\mathrm{V}_{\mathrm{c}}-\mathrm{V}_{\mathrm{a}}\right)$ was $c a .50 \mathrm{mV}$ higher than $\left(\mathrm{V}_{\text {cell }}+\mathrm{IR}\right)$, i.e. $\mathrm{V}_{\mathrm{c}}$ and $V_{a}$ partially sense the potentials of the cathode and the anode. The distortions of the impedance responses were caused by the frequency dependent potential distributions in the electrolyte. As the potential distribution in the electrolyte is related to the anode and cathode, the impedance spectrum between $R_{a}$ and 
$\mathrm{RE}_{\mathrm{c}}$ can be attributed to the response of the electrolyte and the "crosstalk" between anode and cathode through the electrolyte. By subtracting the impedance response of $\mathrm{RE}_{\mathrm{c}} / \mathrm{RE}_{\mathrm{a}}$ from the impedance responses of the anode vs. $\mathrm{RE}_{\mathrm{c}}$ and cathode vs $\mathrm{RE}_{\mathrm{a}}$, the impedance spectra of anode $v s \mathrm{RE}_{\mathrm{a}}$ and cathode $v s . \mathrm{RE}_{\mathrm{c}}$ are consistent with the overpotentials of anode and cathode measured in the d.c. experiments.

As mentioned in section 3.3, with small MEA misalignments (ca. $0.5 \mathrm{~mm})$, as presented in Fig 8(a), the difference between $\left(\mathrm{V}_{\mathrm{c}}-\mathrm{V}_{\mathrm{a}}\right)$ and $\left(\mathrm{V}_{\text {cell }}+\mathrm{IR}\right)$ is only $30 \mathrm{mV}$. This is good enough to measure the potentials of the single electrodes. However, the magnitude of the cathode impedance spectrum is significant different (but with the same form). This suggests that the impedance spectrum of a single electrode can be optained only when the MEA is optimally misaligned.

Prior simulation studies [9] suggest the primary and secondary potential distributions in thin solid electrolytes are different for planar structure systems and that it is impossible to measure the true impedance of the working electrode in such a configuration; these studies indicate that it is difficult to ensure that the primary and secondary potential distributions are the same, even if the cell geometry is well designed. However, the experimental results presented above suggest that it is possible to locate RE in close proximity to the working electrode (Figure 3b) by optimally misaligning the MEA electrodes to minimize the interferences derived from the response of the electrolyte; the potential difference between $\mathrm{RE}_{\mathrm{a}}$ and $\mathrm{RE}_{\mathrm{c}}$ is primarily dictated by the membrane resistance. The impedance spectrum of the cathode remained unchanged with misalignments of $d \geq 2.5 \mathrm{~mm}$ in the systems tested. Although these experimental results support the majority of the prior simulation results [11-12], there are some discrepancies. These likely originate from the different geometry of the electrodes used (circular in simulation studies and square in this study). As discussed in section 3.3, the real overpotentials of anode and cathode can be determined only when the MEA electrodes were misaligned in a narrow range (to allow the real impedance of anode and cathodes to be measured). However, there have been no simulation studies involving the misalignment of MEA electrodes over such a narrow range.

Based on the analysis above, the impedance spectra of the anode $v s . \mathrm{RE}_{\mathrm{a}}$ and the cathode $v s . \mathrm{RE}_{\mathrm{c}}$ can be considered as the real impedance spectra of the electrodes when the MEA is misaligned by $\mathrm{d}=1.5-2.0$ $\mathrm{mm}$ in the systems studied. The results from comprehensive utilisation of the REs in fuel cell testing (Figure 14) show that three different "types" of impedance spectra can be identified. The time constant of 
cathode arc was frequency dependent, whereas the time constant of anode arc was relatively insensitive to frequency with different constant current cell discharges. The anode impedance response contains significant and complex mass transport interferences due to the water generation at anode [16]. The $\mathrm{RE}_{\mathrm{c}} / \mathrm{RE}_{\mathrm{a}}$ impedance spectra exhibit an inductive loop at lower frequencies.

Assigning the distortion of impedance responses of the anode and cathode to the frequency dependent response of electrolyte facilitates interpretation of the results; small and controlled MEA electrode misalignment results in significant differences between the impedance spectra vs. $R_{a}$ and $R_{c}$ (the potential of cathode inert area is dominated by cathode and the potential of anode inert area is dominated by anode). The small magnitude impedance of the cathode $v s$. $\mathrm{RE}_{\mathrm{a}}$ was distorted significantly by inclusion of the frequency dependent electrolyte response i.e. the low-f inductive loop in the $R E_{c} / R E_{a}$ impedance spectra is the source of the inductive loop in the impedance spectrum of cathode $v s . \mathrm{RE}_{\mathrm{a}}$ (Figure 12). The impedances of the anode $v s . \mathrm{RE}_{\mathrm{c}}$ and $\mathrm{RE}_{\mathrm{a}}$ were similar because they were significantly larger in magnitude than the frequency dependent electrolyte responses. It is clear that only when the impedance of the electrode is comparable to or smaller in magnitude than the frequency dependent response of the electrolyte will the distortion of the electrode impedance response become significant. In this study, the performance under d.c. conditions determined the a.c. responses. The potential difference between $R_{a}$ and $R_{c}$ with optimally misaligned MEA electrodes represents the response of the membrane (the ohmic IR drop of the membrane and the contact resistances between the electrodes and membrane) during d.c. discharge and the overpotentials and the impedances of the anode and cathode can be separated; the impedances of the anode and the cathode can be measured on subtracting the frequency dependent response of membrane. Making the stated assumptions, the real impedance of anode and cathode can be determined, i.e. the impedance of anode vs. $\mathrm{RE}_{\mathrm{a}}$ (located in anode area) and the impedance of cathode vs. $\mathrm{RE}_{\mathrm{c}}$ (located in cathode area) represent the real impedance of anode and cathode respectively when the MEA is optimally misaligned. This is an important result which makes it clear that optimal misalignment of the MEA is necessary to determine the impedance of a single electrode and that it is possible to get the impedance of a single electrode when using the applicant-relevant planar MEA configurations.

The d.c. results suggest that if membrane resistance and contact resistance between the active electrode and membrane themselves are not frequency dependent, the high frequency resistance in the impedance 
spectrum between $\mathrm{RE}_{\mathrm{c}}$ and $\mathrm{RE}_{\mathrm{a}}$ will be considered as the resistance of the membrane and the contact resistance between the active electrode and membrane; the high frequency resistance of the impedance spectrum between $\mathrm{RE}_{c}$ and $\mathrm{RE}_{\mathrm{a}}$ is equal to $\mathrm{R}_{\text {cell }}$. This cannot, however, be true because the high frequency resistance (from the $x$-axis intercept) of the cathode $v s . \mathrm{RE}_{\mathrm{c}}$ (or anode $v s . \mathrm{RE}_{\mathrm{a}}$ ) is dependent on the exact position of the RE. In Figure 9(b), where RE3 was closer to the cathode than RE1 the high frequency resistance of cathode vs. RE3 was smaller (similar results were obtained with the other configurations defined in Scheme 1). The high frequency resistance shifted according to the potentials of the REs because they exhibit a small variation when located at different positions within the same inactive area. The results in section 3.3 indicate that the potentials within the cathode inactive area decreased, and the potentials within the anode inactive area increased, when shifting the location further away from MEA edge. This is indicative of the REs not being located exactly at the equipotential surface of the electric field (Figure 3), due to the presence of stray currents in the electrolyte. The potential difference between $\mathrm{RE}_{\mathrm{c}}$ and $\mathrm{RE}_{\mathrm{a}}$ was smaller than the assumed potential difference between the two equipotential surfaces; the high frequency ( $x$-axis intercept) resistance of the $\mathrm{RE}_{\mathrm{c}} / \mathrm{RE}_{\mathrm{a}}$ impedance response will consequently be smaller than the assumed resistance of the membrane and the contact resistances between the electrodes and membrane. This makes the physical meaning of high frequency resistances measured using the REs ambiguous.

\section{Conclusions}

The a.c. impedance response of an electrode can be determined when measured vs. a reference electrode located with an area of the membrane that is adjacent to the electrode. Deliberate and optimal misalignment of the MEA electrodes ensures that the potential in the inactive electrolyte area adjacent to the cathode (the cathode area) is dominated by cathode and the potential at the inactive electrolyte area adjacent to the anode (the anode area) is dominated by anode when conducting both d.c. and a.c. electrochemical experiments. $V_{\mathrm{REa} / \mathrm{REc}}$, the potential between reference electrodes located in the anode $\left(\mathrm{RE}_{\mathrm{a}}\right)$ and cathode $\left(\mathrm{RE}_{\mathrm{c}}\right)$ areas, relates to the IR drop of the electrolyte and contact resistances between the electrodes and the electrolyte. The difference between the tested potential of cathode $\mathrm{vs}_{\mathrm{C}} \mathrm{E}_{\mathrm{c}}$ minus the potential of anode vs. $\mathrm{RE}_{\mathrm{a}}\left(\mathrm{V}_{\mathrm{c}}-\mathrm{V}_{\mathrm{a}}\right)$ and the IR corrected cell potential $\left(\mathrm{V}_{\text {cell }}+\mathrm{IR}\right)$ can be used to judge the optimal misalignment 
of the MEA. When $\left(\mathrm{V}_{\mathrm{c}}-\mathrm{V}_{\mathrm{a}}\right) \approx\left(\mathrm{V}_{\text {cell }}+\mathrm{IR}\right)$, the overpotentials and impedances of the cathode and anode can be separately measured after subtraction of the frequency dependent response of the electrolyte where appropriate. In the system used in this study, the optimal electrode misalignment is $1.5-2.0 \mathrm{~mm}$. A future study will be conducted to find the relationship between $d$ and $L$ to guide the misalignment of MEA in different systems.

Based on this study, to obtain the real potential and impedance of a single fuel cell electrode containing planar MEAs we suggest:

1. Locate two spatially separated REs in anode and cathode inactive areas of the respectively. To correctly misalign the MEA, a test should be run to make sure that $\left(\mathrm{V}_{\mathrm{c}}-\mathrm{V}_{\mathrm{a}}\right) \approx\left(\mathrm{V}_{\text {cell }}+\mathrm{IR}\right)$ to determine the optimal misalignment distance $d$. The impedance of anode and cathode may be underestimated with over misalignment or overestimated with not enough misalignment.

2. The impedance and potential of anode is obtained by measuring the anode properties $v s . R_{a}$ while the impedance and potential of cathode is obtained by measuring the cathode properties $v s . \mathrm{RE}_{\mathrm{c}}$. These are the real impedance and potentials of single electrodes because the response due to the membrane is already subtracted from the response between the single electrodes and REs (anode $v s . \mathrm{RE}_{\mathrm{a}}$ and cathode $v s . \mathrm{RE}_{\mathrm{c}}$ ) due to the optimal misalignment of the MEA.

\section{Acknowledgement}

The authors thank the Engineering and Physical Sciences Research Council (UK, Grant EP/F027524/1) and the Defence Science and Technology Laboratory for funding. Prof. Anthony Kucernak (Imperial College London) is thanked for discussions on aspects of reference electrodes.

\section{References}

[1] Sh. F. Lu, J. Pan, A. Huang, L. Zhuang, J. T. Lu, Proc. Natl. Acad. Sci. 105 (2008) 20611.

[2] S. D. Poynton, J. P. Kizewski, R. C.T. Slade, J. R. Varcoe, Solid State Ionics 181 (2010) 219.

[3] L. A. Adams, S. D. Poynton, C. Tamain, R. C. T. Slade, J. R. Varcoe, Chem. Sus. Chem. 1 (2008) 79. 
[4] M. Unlu, J. Zhou, P. A. Kohl, Electrochem. Solid-State Lett. 12 (2009) B27.

[5] M. Nagata, Y. Itoh, H. Iwahara, Solid State Ionics 67 (1994) 215.

[6] J. Winkler, P.V. Hendriksen, N. Bonanos, M. Mogensen, J. Electrochem. Soc. 145 (1998) 1184.

[7] S.B. Adler, B.T. Henderson, M.A. Wilson, D.M. Taylor, R.E. Richards, Solid State Ionics 134 (2000)

35.

[8] S.H. Chan, X.J. Chen, K.A. Khor, J. Appl. Electrochem. 31 (2001) 1163.

[9] S.B. Adler, J. Electrochem. Soc., 149 (2002) E166.

[10] J. Rutman, I. Riess, Electrochim. Acta 52 (2007) 6073.

[11] M. Cimenti1, a.c. Co, V.I. Birss, J.M. Hill, Fuel Cells 5 (2007) 364.

[12] M. Cimenti1, V.I. Birss, J.M. Hill, Fuel Cells 5 (2007) 377.

[13] K.A. Sasaki, Y. Hao, S.M. Haile, Phys. Chem. Chem. Phys. 11 (2009) 8349.

[14]G.J. Offer, P. Shearinga, J.I. Golbert, D.J.L. Brett, A. Atkinson, N.P. Brandon, Electrochim. Acta 53 (2008) 7614.

[15] P. Piela, T.E. Springer, J. Davey, P. Zelenay, J. Phys. Chem. C 111 (2007) 6512.

[16] R. Zeng, S.D. Poynton, J.P. Kizewski, R.C.T. Slade, J.R. Varcoe, Electrochem. Commun. 12 (2010) 823.

[17] J.R. Varcoe, R.C.T. Slade, Electrochem. Commun. 8 (2006) 839.

[18] J.R. Varcoe, R.C.T. Slade, E.L.H. Yee, Chem. Commun. (2006) 1428.

[19] G. Li, P.G. Pickup, Electrochim. Acta 49 (2004) 4119.

[20] Y. Tsutsumi, S. Ono, M. Eguchi, Electri. Eng. Japan 172 (2010) 10.

[21] S. Uhm, H.J. Lee, J. Lee, Phys. Chem. Chem. Phys. 11 (2009) 9326.

[22] S. Uhm, S.T. Chung, J. Lee, J. Power Sources 178 (2008) 34. 
Scheme 1. The locations of the RE and the anode and cathode electrode alignments used for fuel cell testing.

Fig. 1. The comparison of the (Pt)PdH reference electrode and $\mathrm{Ag} / \mathrm{AgCl}$ reference electrode in aqueous $\mathrm{H}_{2} \mathrm{SO}_{4}$ and $\mathrm{KOH}$ (both $1 \mathrm{~mol} \mathrm{dm}{ }^{-3}$ ).

Fig. 2. The polarization curve and the anode and cathode potentials $v$ s. different REs. $T_{\text {cell }}=50^{\circ} \mathrm{C}$, flow rates $\left(\mathrm{H}_{2}\right.$ and $\left.\mathrm{O}_{2}\right)=400 \mathrm{~cm}^{3} \mathrm{~min}^{-1}$, $\mathrm{RH}=100 \%$, and no back pressurization.

Fig. 3. The idealised equivalent circuit descriptions of the cell configurations.

Fig. 4. The potentials between different REs located at the cathode and anode inactive areas defined in Scheme 1(d) when the MEA electrodes were misaligned by $2.5 \mathrm{~mm}$. Recorded with a scan rate of $5 \mathrm{mV} \mathrm{s}^{-1}$ on a APEMFC containing $2 \times \mathrm{S} 80$ ( $\$ 0 \mathrm{~m}$ thick) AAEM. Test conditions were as described for Fig. 2. The distances between RE1/RE3 $=9 \mathrm{~mm}$, RE2/RE3 $=2.5 \mathrm{~mm}$, and RE4/RE5 $=8 \mathrm{~mm}$.

Fig. 5. The potentials between RE5/RE2 when the MEA electrodes were aligned as precisely as possible (d $= \pm 0.5 \mathrm{~mm}$ ). Recorded with a scan rate of $5 \mathrm{mV} \mathrm{s}^{-1}$ on an APEMFC of configuration: (a) $1 \times \mathrm{S} 80$ with the electrode configuration defined in Scheme 1a (b) $2 \times$ S80 and Scheme 1a (c) $2 \times$ S80 and Scheme 1b. Test conditions were as described for Fig. 2.

Fig. 6. The potential distributions in the inactive areas of membrane with: (a) aligned MEA electrodes and (b) MEA electrodes that were misaligned by $\mathrm{d} \mathrm{mm}$.

.Fig. 7. The potential responses on application of constant discharge currents of the: anode $v s$. $\mathrm{RE}_{\mathrm{a}}$, the cathode vs $\mathrm{RE}_{\mathrm{c}}$, between $\mathrm{RE}_{\mathrm{c}}$ and $\mathrm{RE}_{\mathrm{a}}$, and the whole cell (Scheme $1 \mathrm{~d}, \mathrm{~d}=1.5-2.0 \mathrm{~mm}$ ). Test conditions were as described for Fig. 2.

Fig. 8. The cell polarisation curves and the anode and cathode potentials vs. different REs with MEAs that have been misaligned by different $\mathrm{d}$ mm. Test conditions were the same as in Fig. 2 .

Fig. 9. The impedance spectra of the fuel cell and the electrodes vs. different REs on $160 \mathrm{~mA} \mathrm{~cm}{ }^{-2}$ discharge: (a) Scheme 1a using $2 \times$ S80 AAEM as electrolyte and (b) Scheme 1d with the MEA electrodes misaligned by $+2.5 \mathrm{~mm}$ using $2 \times$ S80 AAEMs as electrolyte. Test conditions were as described for Fig. 2. 
Fig. 10. The impedance spectra vs. different REs located at different areas of the MEAs with electrodes aligned as precisely as possible using $2 \times$ S80 AAEMs as electrolyte (Scheme 1a) at: (a) $40 \mathrm{~mA}$ $\mathrm{cm}^{-2}$ and (b) $240 \mathrm{~mA} \mathrm{~cm}{ }^{-2}$. Test conditions were as described for Fig. 2.

Fig. 11. Typical impedance spectra vs. different REs that were located: (a) in the same inactive area of a MEA misaligned by 2.5 - 3.0mm; and (b) in different inactive areas of a MEA misaligned by 1.5 $2.0 \mathrm{~mm}$ (Scheme 1d). The fuel cell was discharged at $80 \mathrm{~mA} \mathrm{~cm}$. Test conditions were as described for Fig. 2.

Fig. 12. The impedance spectra of the fuel cell, cathode vs. $\mathrm{RE}_{\mathrm{a}}$ and $\mathrm{RE}_{\mathrm{c}}$, and anode $v s . \mathrm{RE}_{\mathrm{a}}$ and $\mathrm{RE}_{\mathrm{c}}$ with a MEA misaligned by $\mathrm{d}=1.5-2.0 \mathrm{~mm}$ (Scheme 1d). The fuel cell was discharged at $160 \mathrm{~mA} \mathrm{~cm}{ }^{-2}$. Test conditions were as described for Fig. 2.

Fig. 13. The impedance spectra of (a) the fuel cell and (b) the cathode $v s . \mathrm{RE}_{\mathrm{c}}$ with misaligned MEAs (Scheme 1d). The fuel cell was discharged at $160 \mathrm{~mA} \mathrm{~cm}{ }^{-2}$. Test conditions were as described for Fig. 2.

Fig. 14. The Nyquist and Bode plots of (a) the fuel cell, (b) the anode vs. $R E_{a}[16]$, (c) the $R E_{c} v s . R_{a}$ and (d) the cathode vs. $\mathrm{RE}_{\mathrm{c}}[16]$ with a MEA misaligned by $\mathrm{d}=1.5-2.0 \mathrm{~mm}$ (Scheme 1d). Test conditions were as described for Fig. 2. 


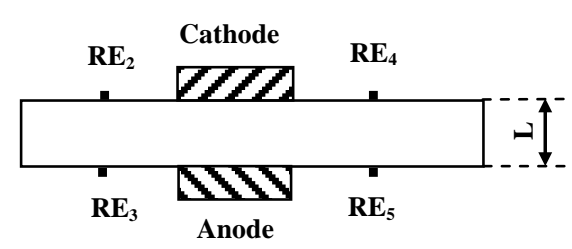

(a)

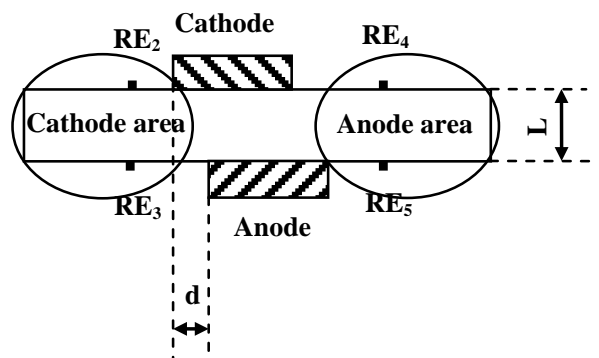

(c)

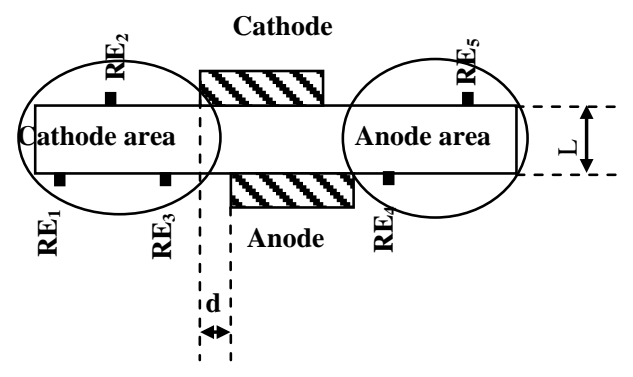

(e)

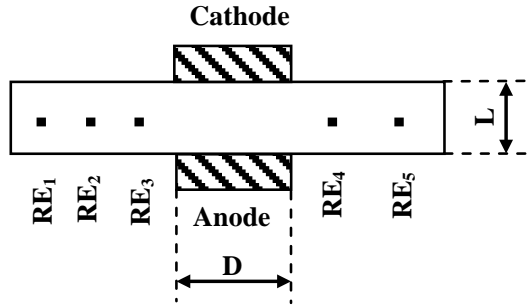

(b)

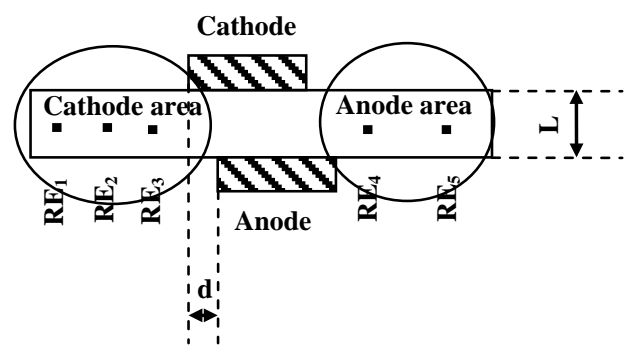

(d)

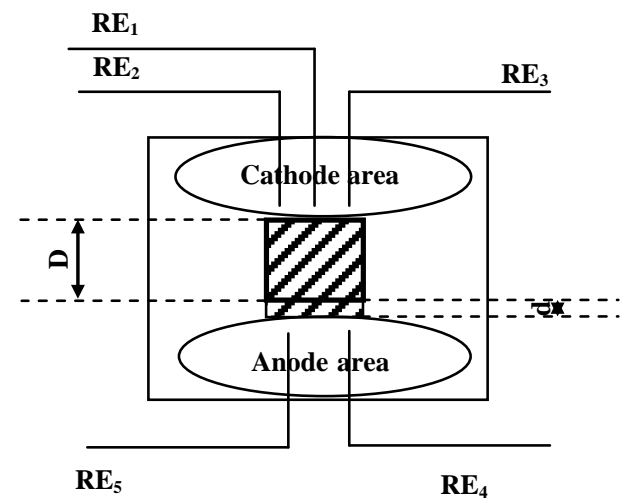

(f)

Scheme 1. 


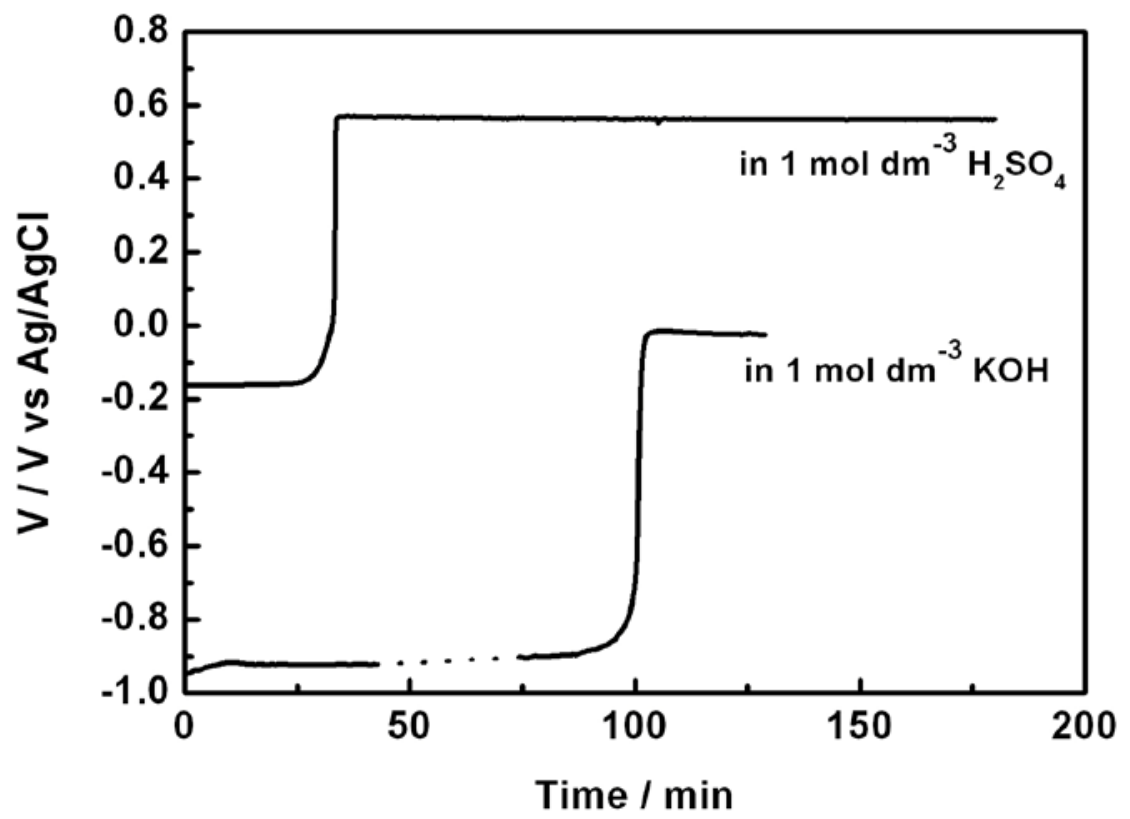

Fig. 1. 


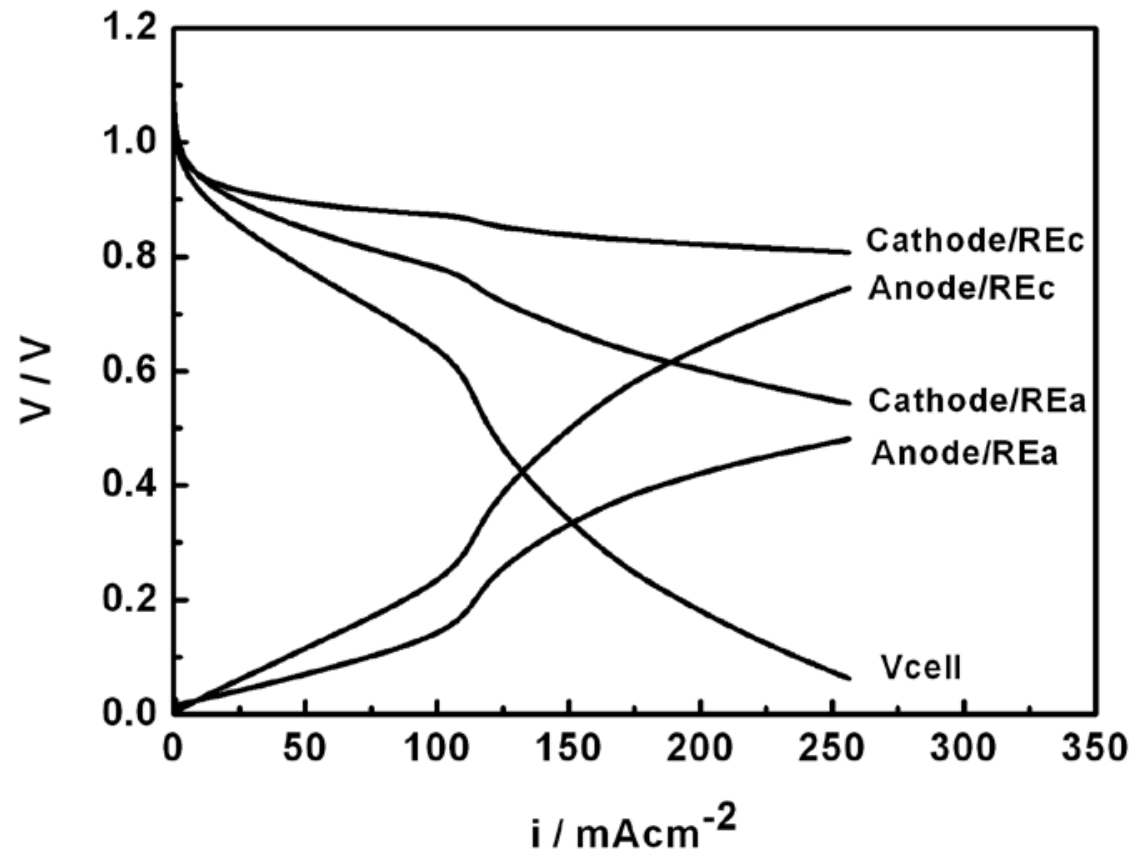

Fig. 2. 


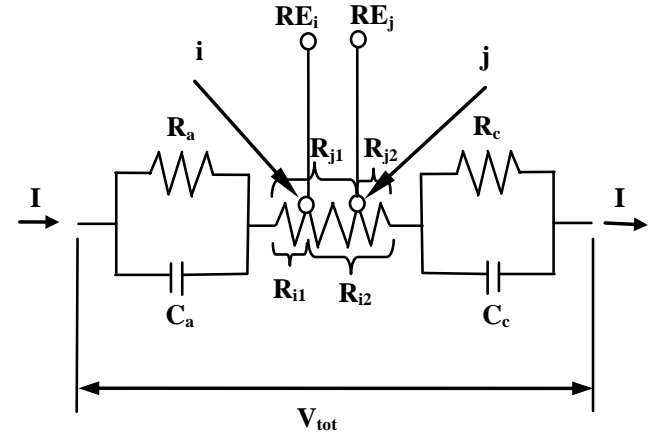

(a)

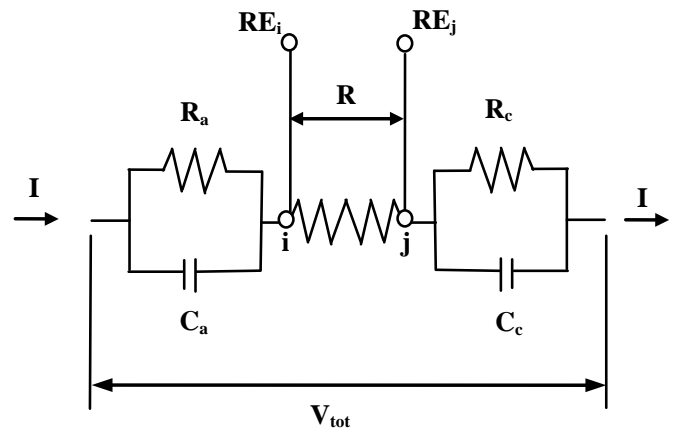

(b)

Fig. 3. 


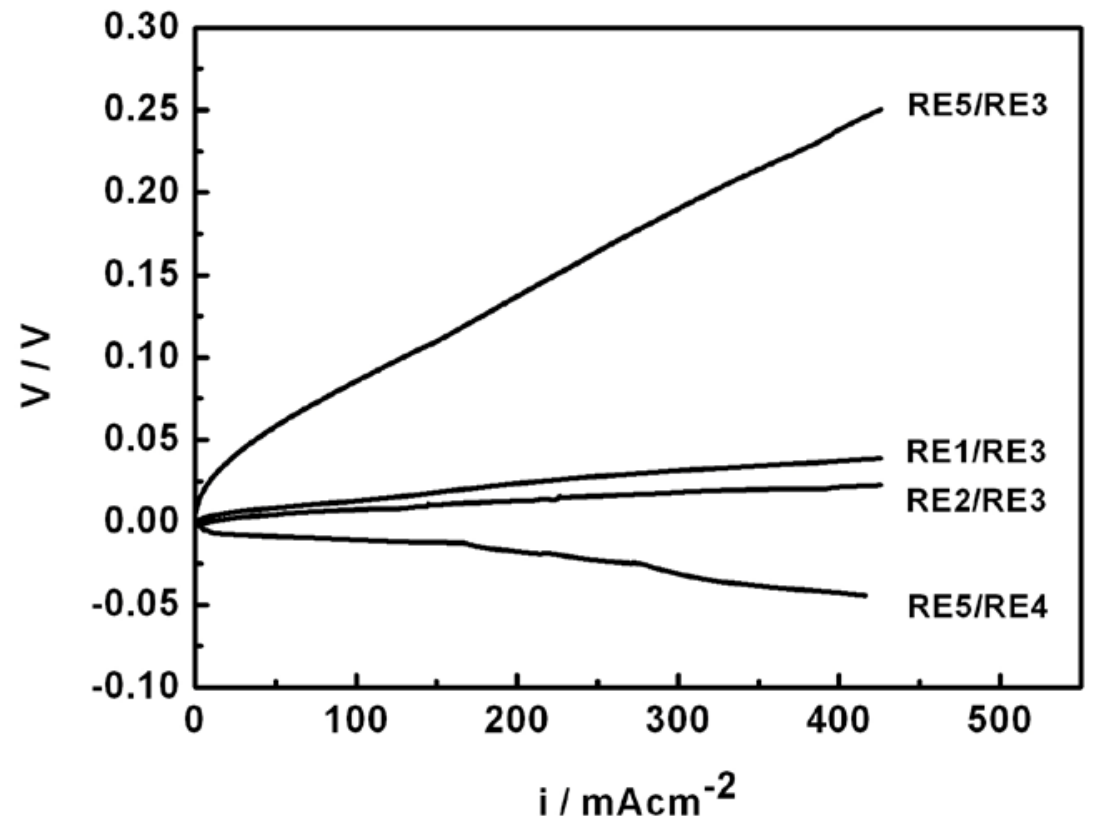

Fig. 4. 


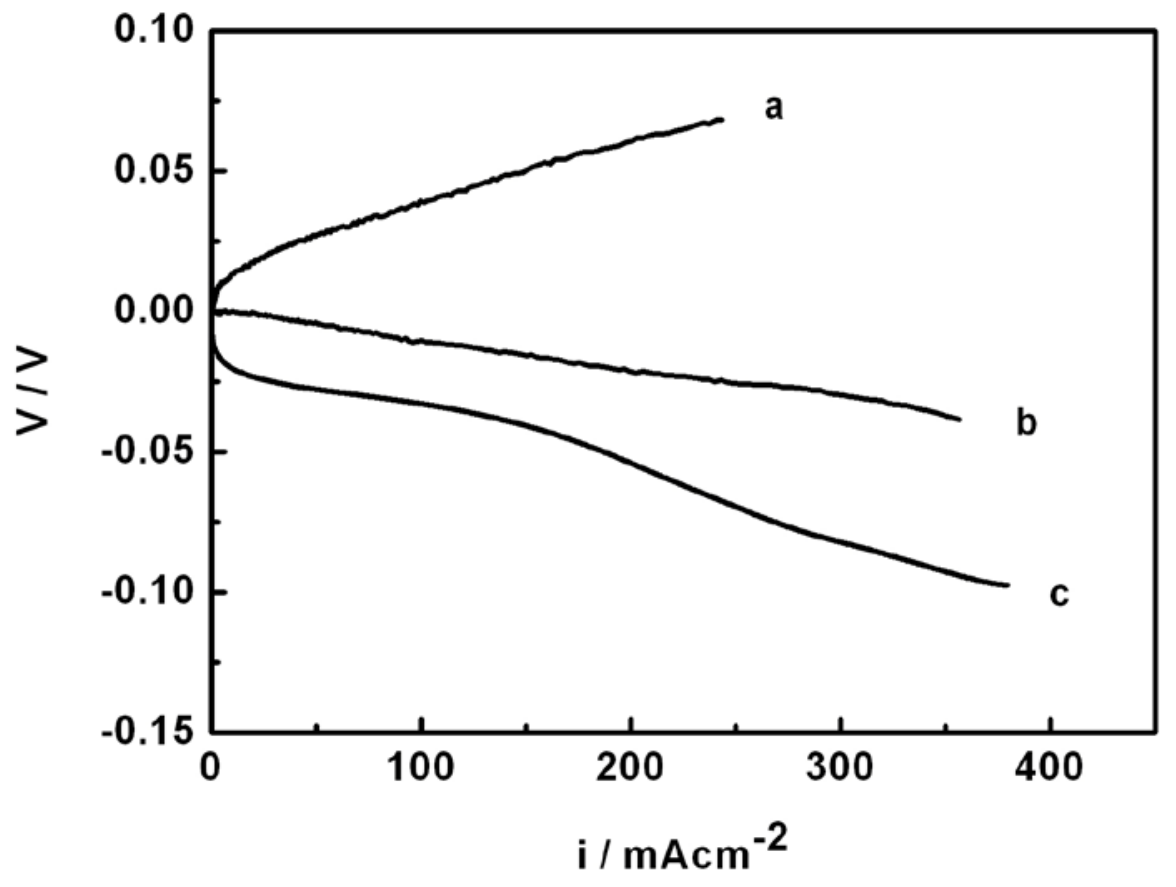

Fig. 5. 


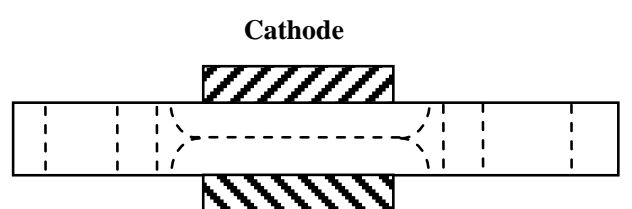

Anode

(a)

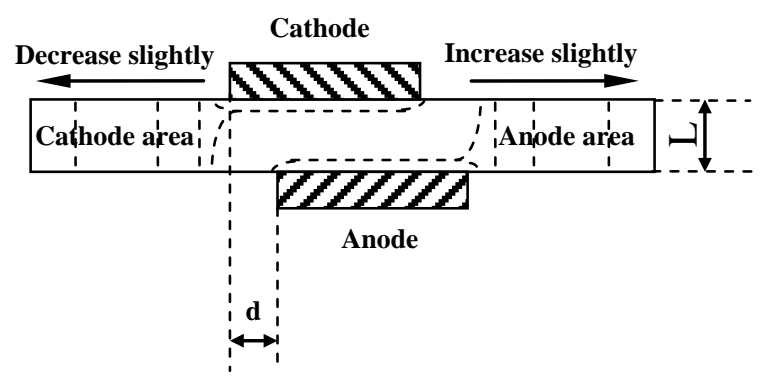

(b)

Fig. 6. 

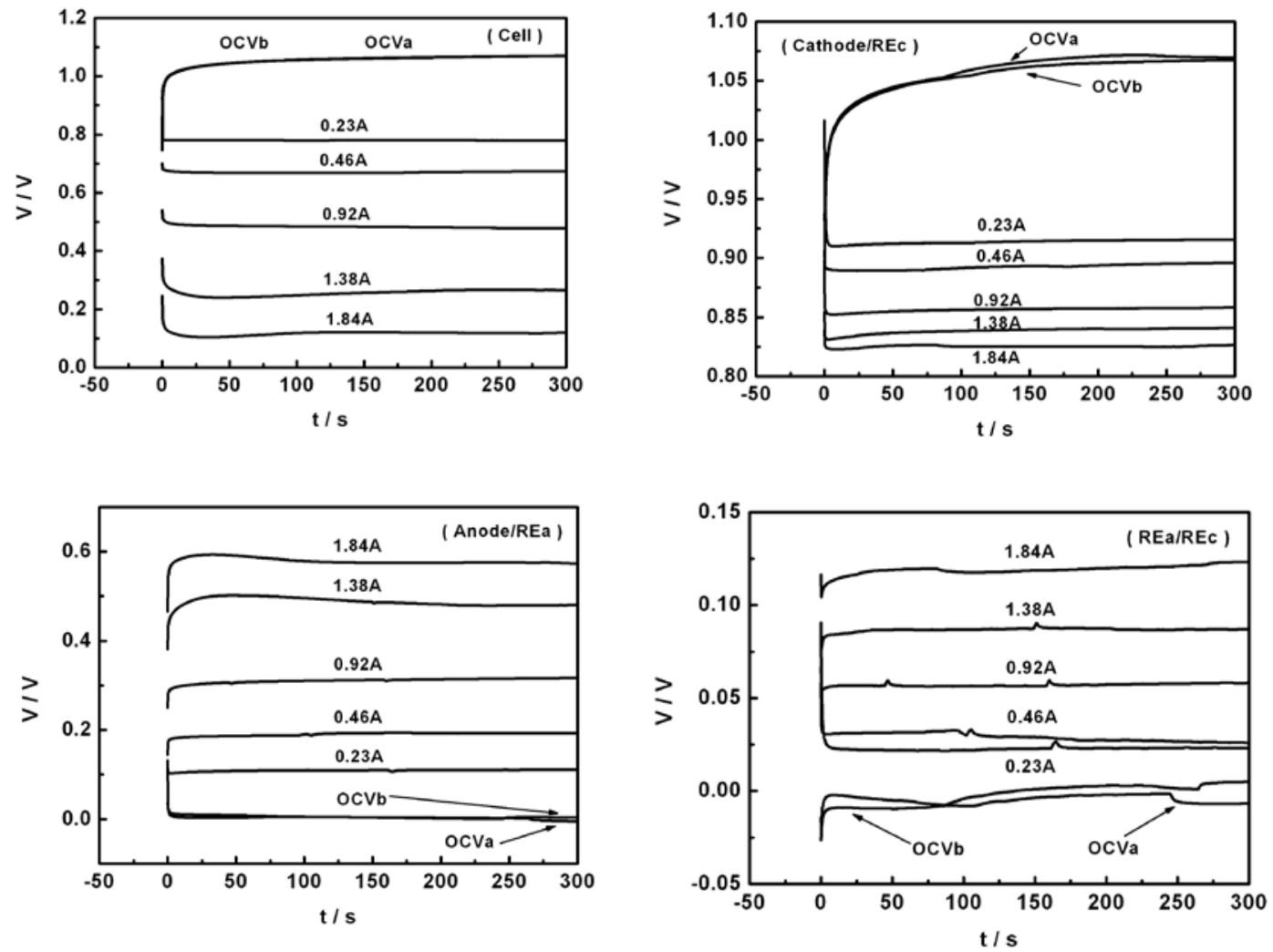

Fig. 7. 

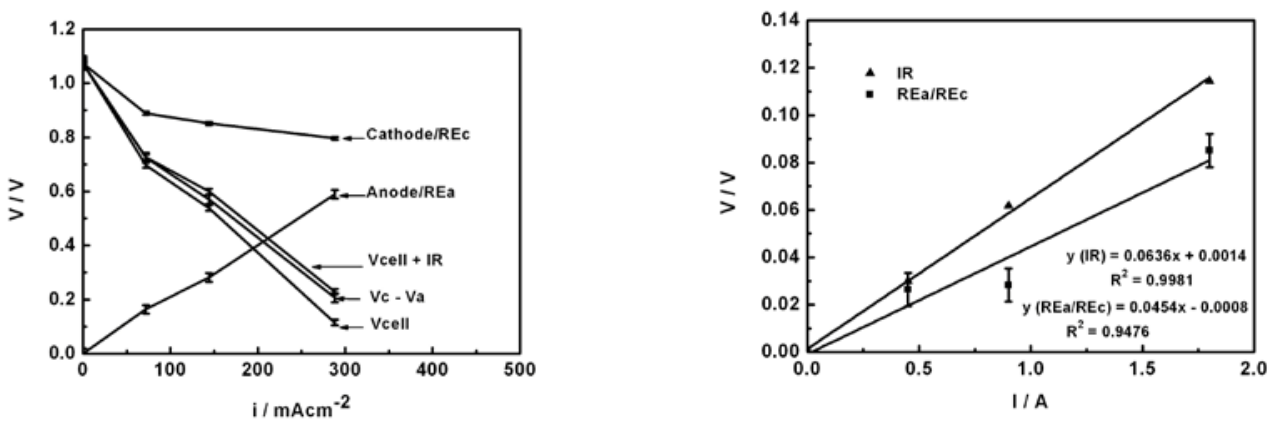

(a) $\mathrm{d}= \pm 0.5 \mathrm{~mm}$ (as precisely as possible)
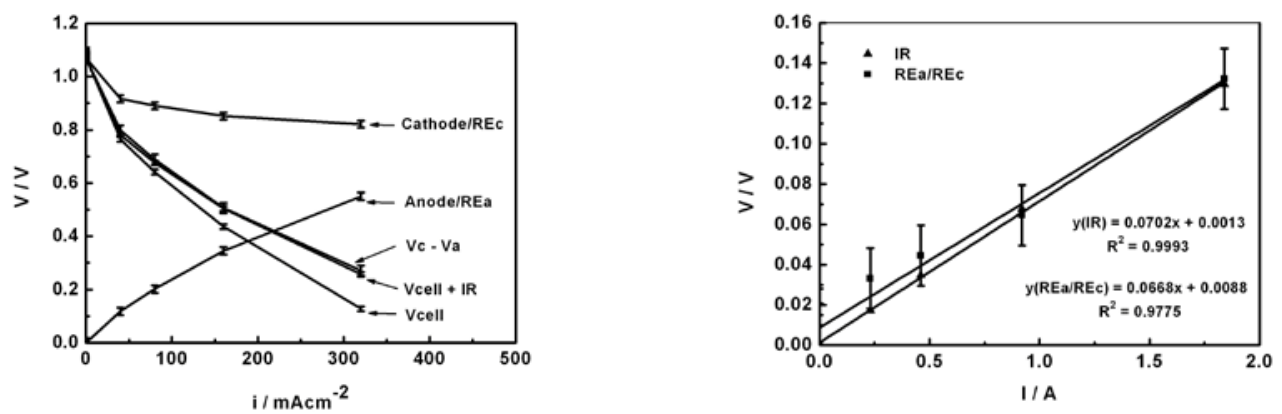

(b) $\mathrm{d}=1.5-2.0 \mathrm{~mm}$
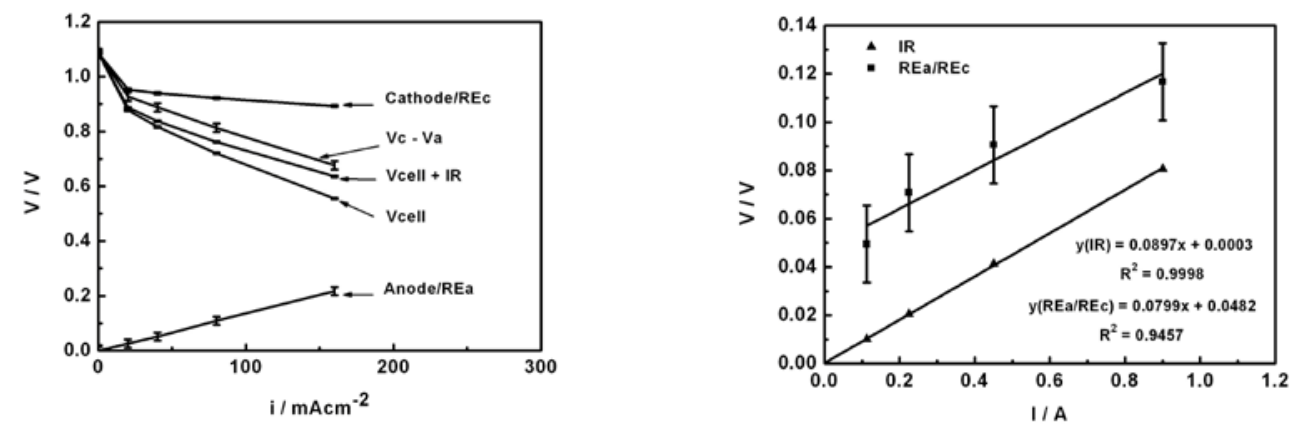

(c) $\mathrm{d}=2.5-3.0 \mathrm{~mm}$
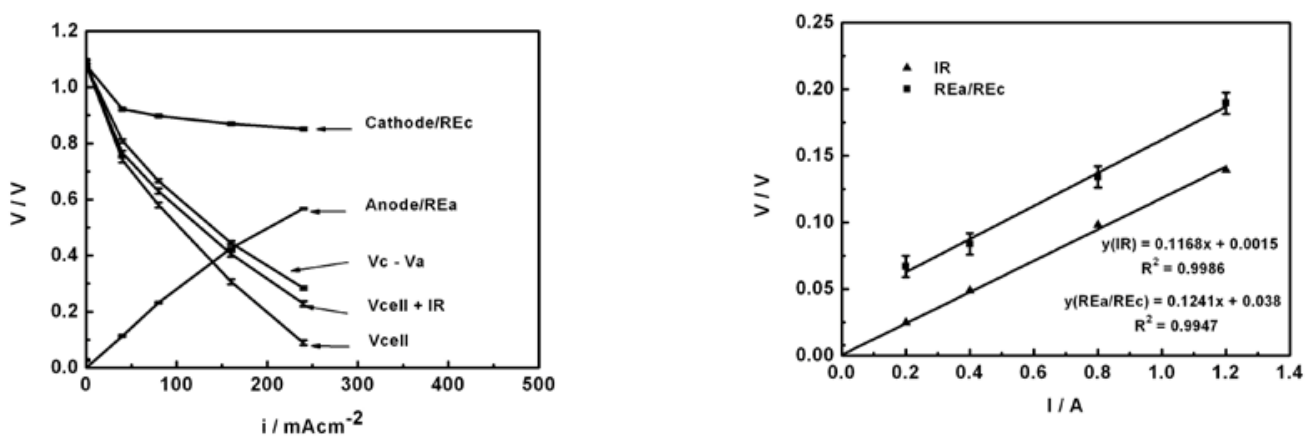

(d) $d=5.0-5.5 \mathrm{~mm}$

Fig. 8. 

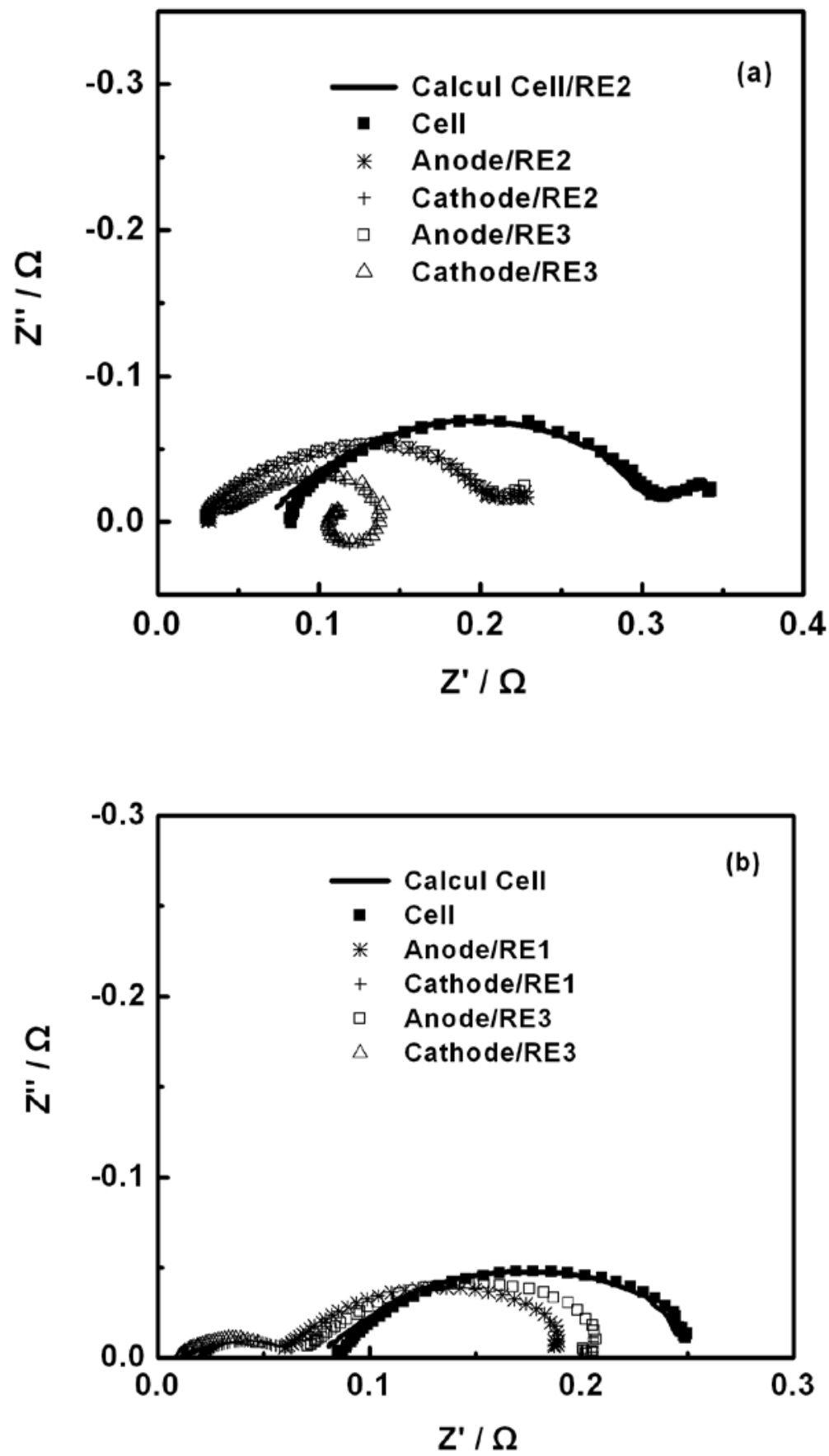

Fig. 9. 


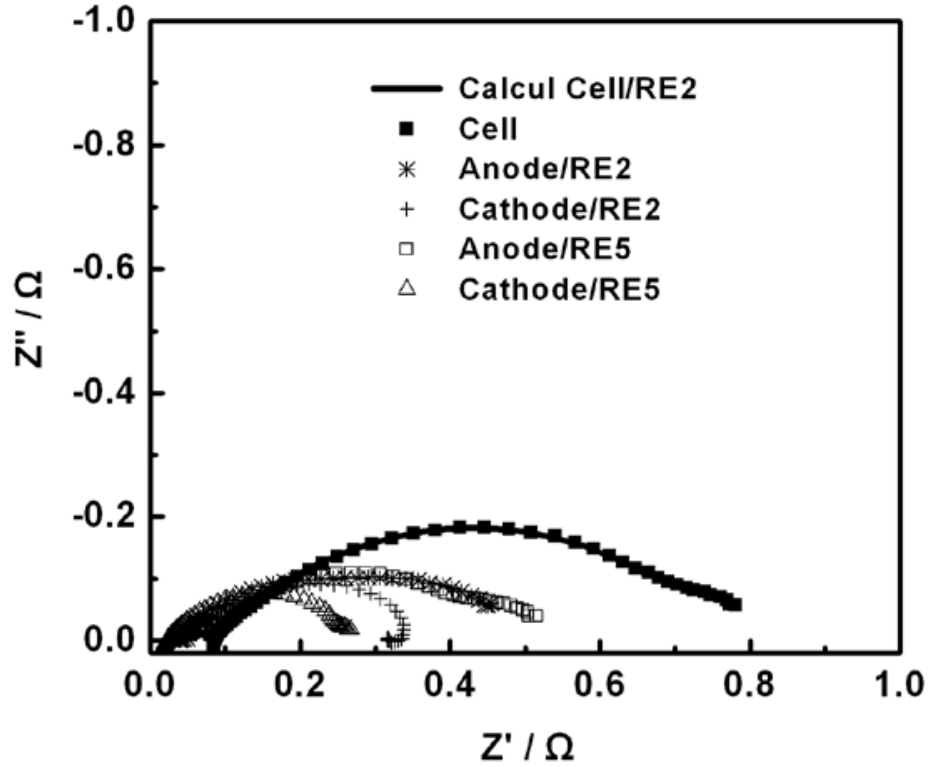

(a)

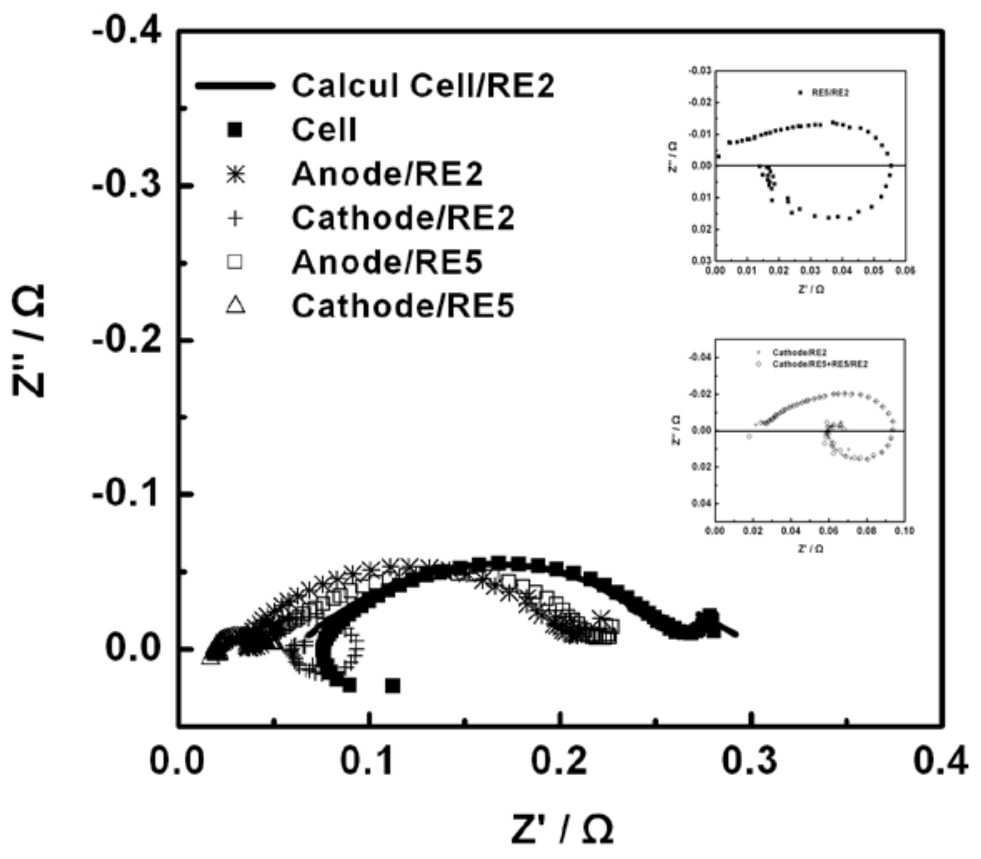

(b)

Fig. 10. 

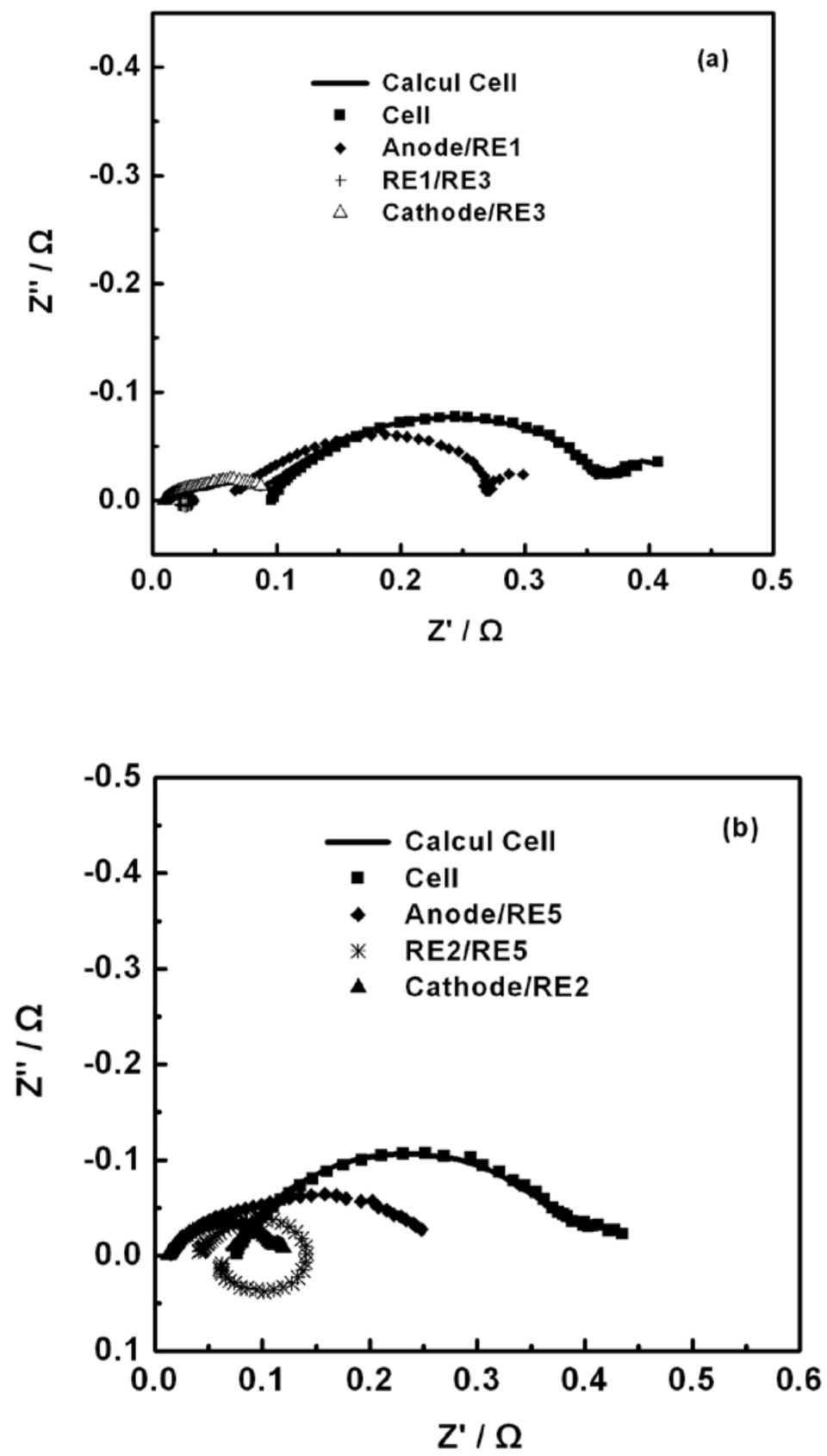

Fig. 11. 


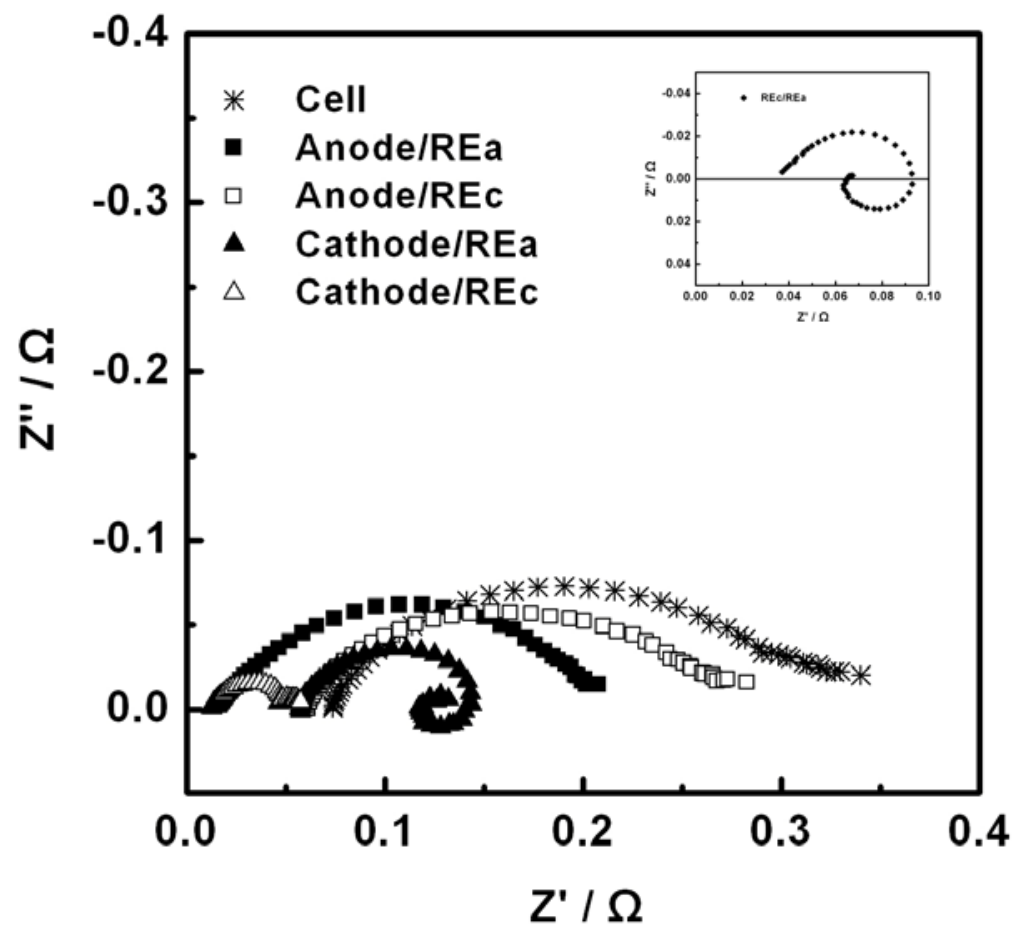

Fig. 12. 

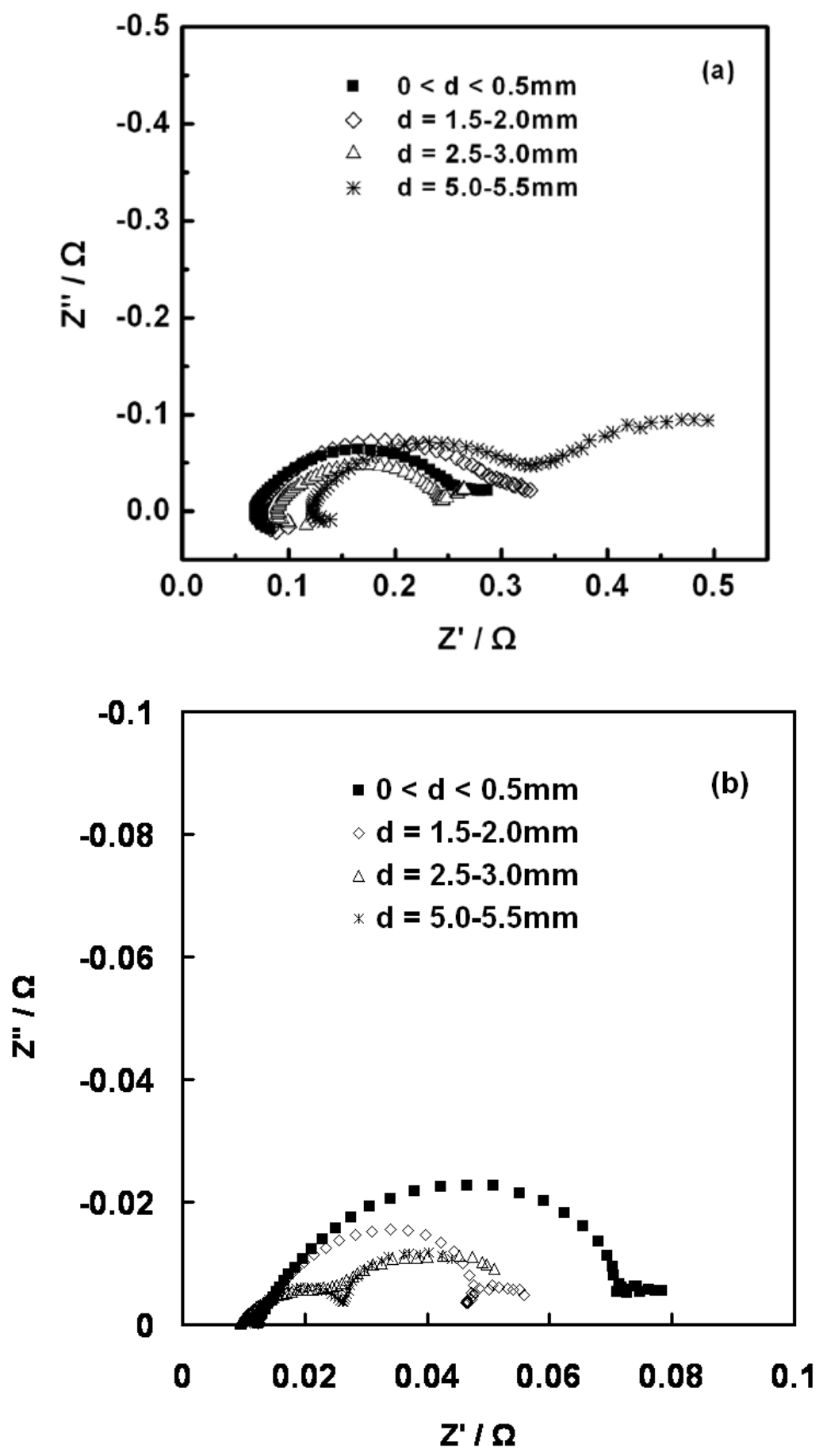

Fig. 13. 

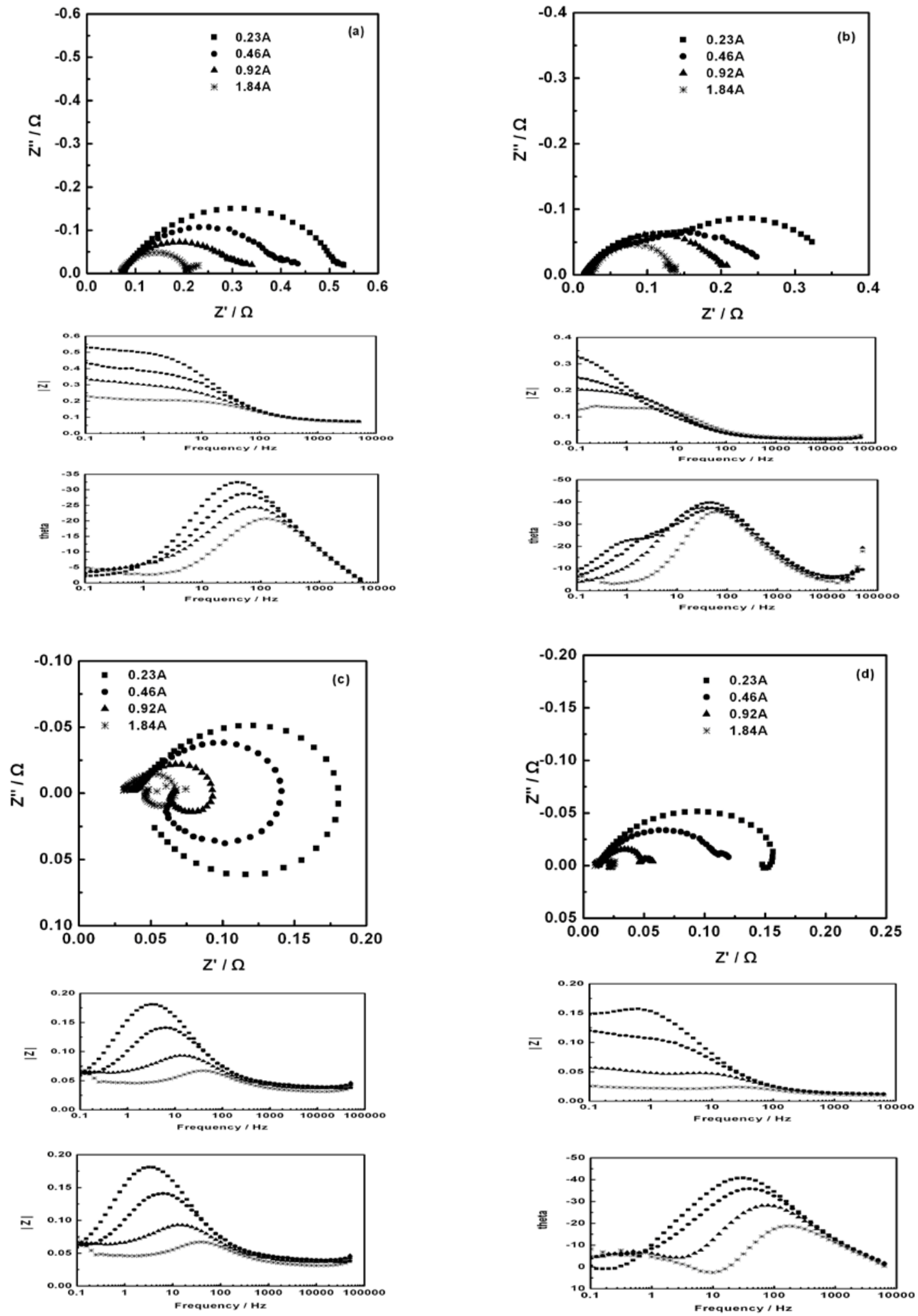

Fig. 14. 